\title{
STUDY OF THE EFFECT OF HUMIDITY, PARTICLE HYGROSCOPICITY AND SIZE ON THE MASS LOADING CAPACITY OF HEPA FILTERS (U)
}

by

Ajay Gupta

WSRC Contact: Paul Monson

Westinghouse Savannah River Company

Savannah River Site

Aiken, South Carolina 29808
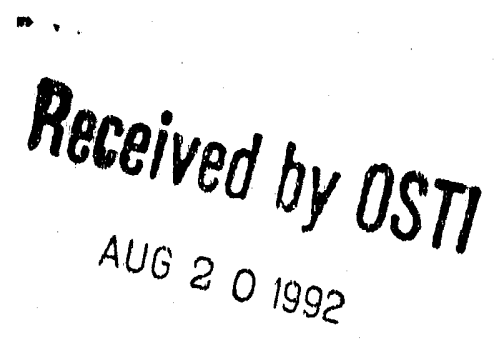

A paper proposed for presentation at the 1992 ASME Winter Annual Meeting Anaheim, California

November $8-13,1992$

and for publication in the proceedings

This paper was prepared in connection with work done under Contract No. DE-AC09-89SR18035 with the U.S. Department of Energy. By acceptance of this report, the publisher and/or recipient acknowledges the U.S. Government's right to retain a nonexclusive, royalty-free license in and to any copyright covering this report, along with the right to reproduce and to authorize others to reproduce all or part of the copyrighted report. 


\title{
STUDY OF THE EFFECT OF HUMIDITY, PARTICLE HYGROSCOPICITY AND SIZE ON THE MASS LOADING CAPACITY OF HEPA FILTERS
}

\author{
A thesis submitted to the \\ Division of Graduate Studies and Research \\ of the University of Cincinnati \\ in partial fulfillment of the \\ requirements for the degree of \\ Master of Science \\ in the Department of Civil and Environmental Engineering \\ of the College of Engineering \\ 1992 \\ by \\ Ajay Gupta \\ Bachelor of Technology \\ Indian Institute of Technology, Delhi, India, 1987.
}

Committee Chair : Professor Pratim Biswas 
This work is dedicated

to

my parents and my brother whose patience, support and hope always

be a source of inspiration. 


\section{Disclabmen}

$\pi$ is report wes propand as an scoount of work sponsored by an agency of the Unlled Stales covernment. Welther the Uniled stales Covemment nor any apancy thereod, nor any of their employees, makes any warranty, express or umplled, or essume any lodis llabilly or responsiblity for the accuracy,

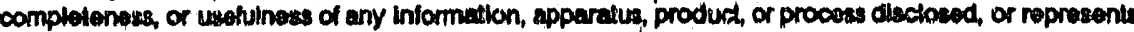

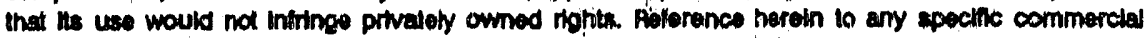

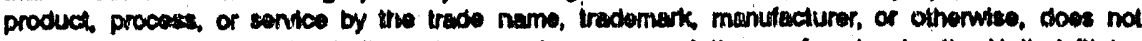
necessartly consthute or imply is endorsenvert, recommendation, of fravoring by the United Stales sovernmont or any agency thersod. The vew and opinions of authors expressed hereln do not necarsarily state or roflect those of the United Stules Government or any apency thereof. 


\section{ABSTRACT}

The effect of humidity, particle hygroscopicity and size on the mass loading capacity of glass fiber HEPA filters has been studied. At humidities above the deliquescent point, the pressure drop across the HEPA filter increased non-linearly with the areal loading density (mass collected/filtration area) of $\mathrm{NaCl}$ aerosol, thus significantly reducing the mass loading capacity of the filter compared to dry hygroscopic or non-hygroscopic particle mass loadings. The specific cake resistance, $K_{2}$, has been computed for different test conditions and used as a measure of the mass loading capacity. $K_{2}$ was found to decrease with increasing humidity for the non-hygroscopic aluminum oxide particles and the hygroscopic $\mathrm{NaCl}$ particles (at humidities below the deliquescent point). It is postulated that an increase in humidity leads to the formation of a more open particulate cake which lowers the pressure drop for a given mass loading. A formula for predicting $K_{2}$ for lognormally distributed aerosols (parameters obtained from impactor data) is derived. The resistance factor, $R$, calculated using this formula was compared to the theoretical R calculated using the Rudnick-Happel expression. For the non-hygroscopic aluminum oxide the agreement was good but for the hygroscopic sodium chloride, due to large variation in the cake porosity estimates, the agreement was poor. 


\section{Acknowledgements}

My sincere thanks and appreciation to ....

My actvisor, Dr. Pratim Biswas, for his guidance in shaping this work.

Dr. Vincent $J$. Novick for providing me an opportunity to carry out experiments at Argonne National Laboratory and guiding me at every stage of this work.

Dr. Timothy Keener and Dr. Tom Hauser for their valuable suggestions.

Mr. Robert C. Haglund for his help in the fabrication of experimental set-up, SEM photographs and cake thickness measurements.

My friends : Amit, Angshuman, Anita, Anup, Bai, Chang, Gera, Godara, Jane, Jeif, Kabra, Kaushik, Kotian, Lu, Masih, Meena, Nikhil, Paul, Phadke, Prakash, Raja, Rohit, Sachin, Sanjay, Satish, Siddhartha, Srikanth, Trilok, Tom, Vibha, Viren, Wen-Yin and Yeh for their support and friendship.

The US Department of Energy, Nuclear Group, for supporting this work under Contract No: W-31-109-ENG-38 with Argonne National laboratory and Contract No: DE-AC09-89SR18035 with Westinghouse Savannah River Company. 


\section{Table of Contents}

Title

Abstract

i

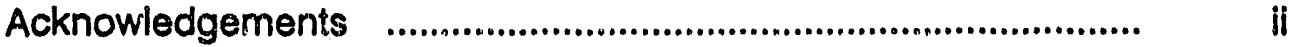

Table of Contents $\quad$..................................................................... ii

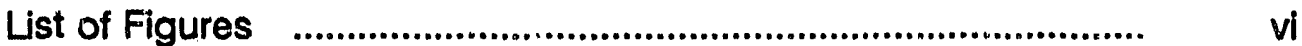

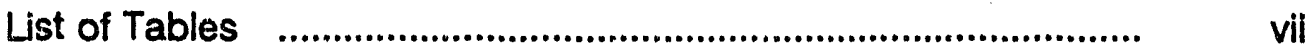

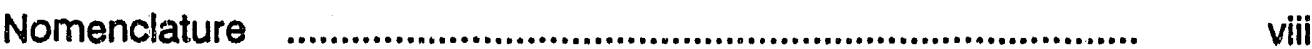

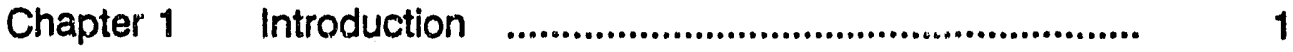

1.1 Background .................................................... 1

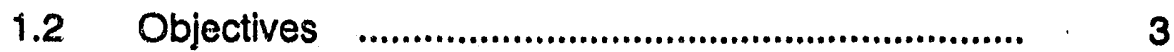

Chapter 2 Expression for specific cake resistance ................. 5 accounting for polydispersiity.

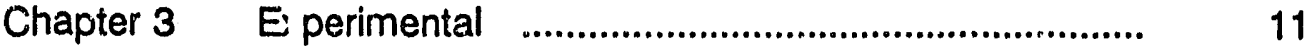

3.1 Experimental apparatus ...................................... 11

3.1.1 Aluminum oxide dispersion .................... 11

3.1.2 Sodium chloride generation .................... 13

3.1.3 Humidification ...................................... 13

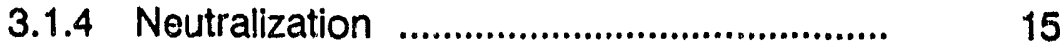

3.1.5 Aerosol sampling ................................... 15 


\section{Table of Contents}

Title

3.1.6 Data Collection ........................................... 16

3.1.7 Particle size measurements ....................... 18

3.1.8 Relative humidity measurements ............... 21

3.2 Design of experiments ............................................. 21

3.3 Estimation of theoretical resistance factor ............. 25

Chapter 4 Results and Discussion ......................................... 26

4.1 Effect of humidity on clean HEPA filter .................. 26

4.2 Results of non-hygroscopic tests .......................... 27

4.3 Hygroscopic aerosols ............................................. 33

4.3.1 Behavior of hygroscopic aerosols in............ 33 humid environments

4.3.2 Estimation of equilibrium contact time $\ldots . . . \quad 35$ between humidity and sodium chloride

4.3.3 Results of hygroscopic tests below .......... 35 deliquescent point

4.3.4 Results of hygroscopic tests above ........... 41 deliquescent point

Chapter 5 Conclusions and Recommendations ...................... 47

References $\quad$...................................................................... 50 


\section{Table of Contents}

Title Page

Appendix-1 Derivation of expression for specific cake .............. : 53

resistance

Appendix-II Properties of test aerosol materials ...................... 57

Appendix-III Humidifier calibration .......................................... 58

Appendix-IV TEOM Characteristics ........................................ 62

IV-1 Performance of TEOM .................. 61

IV-2 TEOM pressure transducer ............. 63 calibrations

Appendix-V Representative sampling characteristics of the $\ldots . . . \quad 65$ sampling chamber

Appendix-VI Impactor Mach number calculations .................... 67

Appendix-VII Calculation of MMD from MMAD ....................... 68

Appendix-VIII Data used for cake porosity estimation ................ $\quad 70$ 


\section{List of Figures}

No.

Title

Page

3.1 Schematic of the experimental system to measure pressure drop as a function mass loading of hygroscopic and nonhygroscopic aerosols at different humidities.

3.2 Schematic of the aerosol generation system used for generating aluminum oxide and sodium chloride aerosols.

3.3 Schematic of the aerosol sampling system.

3.4 Design of a TEOM Filter and the TEOM Oscillating Element. 19

4.1 Measured pressure drop versus areal density for $0.5 \mu \mathrm{m}$ nominal MMD aluminum oxide at different humidities.

4.2 Measured pressure drop versus areal density for $1.0 \mu \mathrm{m}$ nominal MMD aluminum oxide at different humidities.

4.3 Comparison of experimental and theoretical resistance factor, $R_{c}$ for non-hygroscopic aluminum oxide.

4.4 Measured pressure drop versus areal density for $0.5 \mu \mathrm{m}$ nominal MMD NaCl at different humidities.

4.5 Measured pressure drop versus areal density for $1.0 \mu \mathrm{m}$ nominal MMD NaCl at different humidities.

4.6 Comparison of experimental and theoretical resistance factor, $R_{c}$ for hygroscopic sodium chloride.

4.7 Measured pressure drop versus areal density curve

for $\mathrm{NaCl}$ droplets of $1.26 \mu \mathrm{m}$ (initial size $=0.5 \mu \mathrm{m}$ ) at $80 \% \mathrm{RH}$.

4.8 Measured pressure drop versus areal density curve for $\mathrm{NaCl}$ droplets of $1.62 \mu \mathrm{m}$ (initial size $=0.5 \mu \mathrm{m}$ ) at $90 \% \mathrm{RH}$.

4.9 Measured pressure drop versus areal density curve for $\mathrm{NaCl}$ droplets of $3.12 \mu \mathrm{m}$ (initial size $=1.0 \mu \mathrm{m}$ ) at $80 \% \mathrm{RH}$.

4.10 Measured pressure drop versus areal density curve for $\mathrm{NaCl}$ droplets of $3.77 \mu \mathrm{m}$ (initial size $=1.0 \mu \mathrm{m}$ ) at $90 \% \mathrm{RH}$.

III-1 Humidifier calibration curve 


\section{List of Tables}

No.

Title

Page

3.1 Equipment and materials used in the experiments

3.2 Experimental conditions for the non-hygroscopic aluminum oxide and the hygroscopic sodium chloride test aerosol.

4.1 Variation of clean filter resistance with humidity.

4.2 Measured particle size, geometric standard deviation, specific cake resistance and resistance factors for aluminum oxide test aerosol.

4.3 Measured particle size, geometric standard deviation, specific cake resistance and resistance factors for sodium chloride test aerosol.

II-1 Properties of hygroscopic sodium chloride

II-2 Properties of non-hygroscopic aluminum oxide

III-1 Humidifier calibration data (Raw)

III-2 Humidifier calibration data (Corrected)

IV-1 TEOM performance data

IV-2 TEOM pressure transducer calibration data

VII-1 Calculated MMD for the non-hygroscopic and hygroscopic tests

VIII-1 Cake thickness and porosity data for $47 \mathrm{~mm}$ filters 


\section{Nomenclature}

\begin{tabular}{|c|c|}
\hline A & Filtration Area $\left(\mathrm{cm}^{2}\right)$ \\
\hline C & Cunningham Slip Correction Factor \\
\hline$d_{g}$ & Geometric Mean Particle Diameter $(\mathrm{cm})$ \\
\hline$d_{p}$ & Particle Diameter $(\mathrm{cm})$ \\
\hline$d_{m m}$ & Mass Median Diameter $(\mathrm{cm})$ \\
\hline$K_{1}$ & Clean Filter Resistance $\left(\mathrm{g} \mathrm{cm}^{-2} \mathrm{~s}^{-1}\right)$ \\
\hline$k_{2}$ & Measured Specific Cake Resistance $\left(\mathrm{s}^{-1}\right)$ \\
\hline $\mathrm{K}_{\mathrm{zc}}$ & Polydisperse Specific Cake Resistance $\left(\mathbf{s}^{-1}\right)$ \\
\hline$K_{2 \text { SIokes }}$ & Stokes Specific Cake Resistance $\left(\mathrm{s}^{-1}\right)$ \\
\hline M & Total Mass of Particles Collected on the Filter (g) \\
\hline $\mathbf{R}$ & Resistance Factor \\
\hline $\mathrm{R}_{\mathbf{S}}$ & Calculated Resistance Factor based on Stokes Formula \\
\hline $\mathrm{R}_{\mathrm{c}}$ & Calculated Resistance Factor including polydispersity \\
\hline v & Filter Media Velocity $\left(\mathrm{cm} \mathrm{s}^{-1}\right)$ \\
\hline$\Delta P$ & Pressure Drop Across Loaded Filter $\left(\mathrm{N} \mathrm{m}^{-2}\right)$ \\
\hline$\Delta P_{\text {fither }}$ & Initial Pressure Drop Across Filter $\left(\mathrm{N} \mathrm{m}^{-2}\right)$ \\
\hline$\Delta P_{\text {cake }}$ & Pressure Drop Across the Particulate Cake $\left(\mathrm{N} \mathrm{m}^{-2}\right)$ \\
\hline \multicolumn{2}{|c|}{ Greek Symbols } \\
\hline$e$ & Porosity of Particle Cake \\
\hline$\mu$ & Gas Viscosity $\left(\mathrm{g} \mathrm{cm}^{-1} \mathrm{~s}^{-1}\right)$ \\
\hline 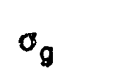 & Geometric Standard Deviation \\
\hline
\end{tabular}




\section{CHAPTER 1}

\section{INTRODUCTION}

\subsection{Background}

High Ehiciency Particulate Air (HEPA) fitters are often used as the primary partlculate contairment devlca in gas clsaning and ventilation systiems. The term "high atficiency" is applled to a fiter capable of remaving $0.3 \mu \mathrm{m}$ dioctyl pithalate (DOP) particles with an efficlency of atleast $99.97 \%$ (Tillery, 1987). As the HEPA fitter removes particles from the gas stream, the initial pressure frop across the filter increases dve to the formation of a particulate cake on its surface. With continued partlculate cake bulldup, the flow rate through the ventilation system decreases. Eventually, clue to pressure drop limitations of the exhaust fan, the gas flow through the filter approaches zero. Sich situations are of serious concern in nuclear installations, especially duing an accident wherein large quantities of radioactive aerosols could be generated (Hasinclever, 1971). In some postulated accident scenarios associated with water cooled nuclear reactors, a large quantity of steam could also be released along with a variety of aerosols. The interaction of water vapor with the generated aerosols may significantly affect the ability of the filtration systems ies malntain sufficlent flow for the entire accident sequence hence contain any aerosol tormed within the reactor bullding. 
In certain previous studies the effects of humiclity on the pressure drop across filters has been sturi'ed. In one of the studles, Durham and Harrington (1971) examined the influence of relative humidity on filtration resistance and efficiency of fabric dust filters. They varied humidity in the range of $20 \%$ to $60 \% \mathrm{RH}$ and observed a decrease in pressure drop across fabric filters when fly ash partifie were used. They did not observe any decrease in the pressure drop for cement dust, pulverized limestone, oi arncrphous silica. In another study, Ariman and Helfritch (1977) examined how chang; in relative r.umidity altered the pressure drop in fabric filters. The test dusts used in the study were fly ash, ground sillica dust and asphalt rock dust. On incressing the humidity in the range of $20 \%$ to $80 \% \mathrm{RH}$, they observed a decreasing trend in the pressure drop for all the test cases.

Rowently Novick and Higgins (1989) and Novick et al. (1990) reported that the pressure drop across a HEPA filter increased non-linearly when sodium chloride ( $\mathrm{NaCl})$ particles from a high humidity aerosol stream were loaded onto the filters. However, they noted that at low humidities (35\%) the increase in thu pressure drop with mass loading remained linear for the $\mathrm{NaCl}$ aerosol. Smith et al. (1990) also investigated the effect of humidity on the pressure drop change across a HEPA filter being loaded with $\mathrm{NaCl}$ aerosol. Experiments were conducted at two average humidities of $80 \%$ (65\% to 99\%) and $14 \%$ (9 to 18\%). Higher pressure drops were reported at higher frumiditles. This was qualliatively attributed to a more effective plugging of filters due to fusing of salt $(\mathrm{NaCl})$ in the presence of molsture. Ricketts et al. (1990) examined the pressure drop across pre-loaded HEPA filters previously used in the ventilation system of their laboratory, under different humidity conditions. They found that the rate and extent of the pressure drop increase was significant only at humidities above $70 \%$. 
Though the above studies have indicated trends, no definite conclusions could be made about the effects of relative humidity on the alterations of pressure drop. Furthermore, the effects of relative humidity are bound to be dependent on the aerosol material properties, such as hygroscopicity and may also depend on the upon the particle size of the aerosol. The apparent contradictions in the effects of humidity on the pressure drop as observed by Smith et al. (1990) and Durham and Harrington (1971), and Ariman and Helfritch (1977) could have been due to differences in the hygroscopicity or size of the test particles.

\subsection{Objectives}

The objective of this study was to determine the effects of humidity on the pressure drop-mass loading characteristics of a HEPA filter vis-a-vis particle hygroscopicity and size. Controlled laboratory experiments were conducted using two sizes $(0.5 \mu \mathrm{m}$ and 1.0 $\mu \mathrm{m}$ nominal mass median diameter) of two different particle materials : non-hygroscopic aluminum oxide and hygroscopic sodium chloride.

The development of an expression for calculating the specific cake resistance using the commonly reported mass median diarneter is presented in Chapter 2 . The expression is valid for lognormally distributed aerosols.

The experimental set up and methodology is discussed in Chapter 3. A modified Tapered Element Oscillating Microbalance (TEOM) was used to measure the pressure drop and mass loading on the HEPA material. Aluminum oxide and sodium chloride were used as the non-hygroscopic and hygroscopic test aerosols respectively. Desired 
levels of relative humidity were attained by mixing humidified air with the aerosol stream.

The experimental results are presented in Chapter 4 . The observed pressure drop versus mass loading characteristics vis-a- vis particle hygroscopicity, relative humidity and particle size are qualitatively explained. Also presented is the comparison of the theoretical resistance factor with the resistance factor obtained from the expression developed in Chapter 2.

Chapter 5 discusses the conclusions and recommendations for future work. Properties of test aerosols, derivation of the expression for specific cake resistance, humidifier calibrations, representative sampling characteristics of the sampling system, results of the TEOM performance tests, TEOM transducer calibrations, impactor Mach number calculations, conversion of MMAD to MMD, and porosity data are presented in Appendices I to VIII. 


\section{CHAPTER 2}

\section{EXPRESSION FOR SPECIFIC CAKE RESISTANCE ACCOUNTING FOR POLYDISPERSITY}

The total pressure drop across a filter, $\Delta P$, is the sum of pressure drops across the filter media, $\Delta P_{\text {fmer }}$ and that across the particulate cake, $\Delta P_{\text {cake }}$. Mathematically, it can be written as

$$
\Delta P=\Delta P_{\text {trtor }}+\Delta P_{\text {caks }}
$$

Assuming the filter media and the particulate cake to be two rigid porous beds superimposed on each other, and flow through them to be laminar, then each component of the total pressure drop can be described by Darcy's law and written as

$$
\begin{gathered}
\Delta P_{\text {fther }}=K_{1} V \\
\Delta P_{\text {cake }}=K_{2} V\left(\frac{M}{A}\right)
\end{gathered}
$$


where $K_{1}$ is the clean filter resistance, $V$ is the filtration velocity, $K_{2}$ is the specific cake resistance, $M$ is the mass deposited and $A$ is the filtration area. $K_{2}$ is generally computed experimentally by using measured values of $\Delta P$ and $\Delta P_{\text {nher }}$ in equations (2.1), (2.2) and (2.3)

$$
K_{2}=\frac{\left(\Delta P-\Delta P_{\text {(nour }}\right)}{V \frac{M}{A}}
$$

The theoretical expression for the specific cake resistance, $K_{2}$, is derived by applying Stokes law to the particles in a cake by assuming that they are monodisperse and sparsely distributed (flow over a particle is not influenced by the presence of other particles). Assuming that there are $\mathrm{N}$ such particles in the cake, the pressure drop is given by

$$
\Delta P_{\text {cake }}=\frac{3 \pi \mu V d_{p} N}{A C}
$$

where $\mu$ is the gas viscosity, $d_{p}$ is the particle size and $C$ is the Cunningham slip correction factor. Rewriting equation (2.5) in terms of the mass of particles collected

$$
\Delta P_{\text {cake }}=\left(\frac{18 \mu}{\rho_{p} d_{p}^{2} C}\right)\left(\frac{V M}{A}\right)
$$

where $\rho_{p}$ is the particle density. Using the definition of the specific cake resistance frum equation (2.4), the following theoretical expression is derived

$$
K_{2_{\text {datax }}}=\left(\frac{18 \mu}{\rho_{p} d_{p}^{2} C}\right)
$$


The specific cake resistance determined using equation (2.7) is the minimum value corresponding to a sparse distribution of monodisperse spherical particles.

Equation (2.7) shows that $K_{2}$ is inversely proportional to the square of particle diameter. If the particles in the cake are not monodisperse, a mean particle diameter must be used. For mass loading studies, the mass median diameter becomes the appropriate choice because it is directly indicative of the particle mass. However, it is not representative of the particle cross sectional area responsible for the drag. Rudnick (1978) suggested that for polydisperse dusts, the volume-length mean diameter should be used to calculate the resistance factor, $R$ (explained later). Since aerosol size distributions are often represented by lognormal functions and the volume-length mean diameter is not commonly reported, an expression for calculating specific cake resistance for the lognormally distributed aerosols is developed in this paper.

Assuming that the size distribution of particles on the cake can be represented by $n(v)$, the pressure drop due to the cake can be computed by integrating equation (2.5) over all particle sizes (or particle volumes)

$$
\Delta P_{\text {care }}=\frac{3 \pi \mu V}{(\pi / 6)^{1 / 3} A} \int_{0}^{\infty} \frac{v^{1 / 3}}{C} n(y) d v
$$

where, $v$ is the particle volume $\left(v=\pi d_{p}{ }^{3} / 6\right)$. Assuming $C$ to be evaluated at the geometric mean diameter, equation (2.8) reduces to

$$
\Delta P_{\text {cake }}=\frac{(162)^{1 / 3}(\pi)^{2 / 3} \mu V}{A} \frac{M_{1 / 3}}{C}
$$


where $M_{1 / 3}$ is the $1 / 3^{\text {rd }}$ volume moment of the aerosol size distribution. For lognormally distributed aerosols the $k^{\text {th }}$ moment, $M_{k}$, is expressed in terms of the zeroth moment, $M_{0}$ (Biswas et al.,1989)

$$
M_{k}=M_{0} v_{g}^{k} \exp \left(4.5 k^{2} \ln ^{2} \sigma_{g}\right)
$$

where $v_{g}$ is the geometric volume mean and $\sigma_{g}$ is the geometric standard deviation. Using $k=1 / 3$ in equation (2.10) and substituting in equation (2.9) we have

$$
\Delta P_{\text {cake }}=\frac{(162)^{1 / 3}(\pi)^{2 / 3} \mu \vee M_{0} V_{0}^{1 / 3}}{A C} \exp \left(0.5 \ln ^{2} \sigma_{g}\right)
$$

Multiplying and dividing equation (2.11) by $M_{1} \rho_{p}$ (=mass collected, $M$ ) and using equation (2.10) we have

$$
\Delta P_{\text {cake }}=\frac{(162)^{1 / 3}(\pi)^{2 / 3} \mu}{\rho_{p} C V_{\sigma}^{2 / 3}}\left(\frac{V M}{A}\right) \exp \left(-4.0 \ln ^{2} \sigma_{g}\right)
$$

Using equation (2.4) an expression for the specific cake resistance, $K_{2 c}$, for a polydisperse aerosol with the slip correction factor evaluated at the mean geometric size can be derived

$$
K_{2 C}=\frac{18 \mu}{\rho_{p} d_{\theta}^{2} C} \exp \left(-4.0 \ln ^{2} \sigma_{\theta}\right)
$$

where $d_{g}$ is the geometric mean diameter of the particle size distribution which can be calculated from mass median diameter obtained from impactor data (Hinds, 1982) 


$$
d_{g}=d_{m m} \exp \left(-3.5 \ln ^{2} \sigma_{\rho}\right)
$$

Substituting in equation (2.13) we get

$$
K_{2 C}=\frac{18 \mu}{\rho_{p} d_{m m}^{2} C} \exp \left(3.0 \ln ^{2} \sigma_{g}\right)
$$

In the limit $\sigma_{\mathfrak{g}} \rightarrow 1$ (monodisperse particles), $K_{2 c}$ in equation (2.15) approaches $K_{2 \text { stokes }}$ in equation (2.7).

In a real cake the particles are not sparsely distributed. On the contrary, they are in close proximity of each other such that the flow around a particle is influenced by the presence of its neighboring particles. This non-ideality results in pressure drops higher than those predicted by equation (2.13). To account for the differences in the experimentally measured value, $K_{2}$ (equation (2.4)) and the theoretically computed value (equation (2.13) or equation (2.7) for monodisperse aerosols) a resistance factor, $R$, is defined

$$
R=R_{C}=\frac{K_{2}}{K_{2 C}} \text { or } R_{s}=\frac{K_{2}}{K_{\text {2stokes }}}
$$

Rudnick (1978) proposed the following expression, based on Happel free surface model, for the determination of theoretical $R$ 


$$
R=\frac{3+2(1-e)^{5 / 3}}{3-4.5(1-e)^{1 / 3}+4.5(1-e)^{5 / 3}-3(1-e)^{2}}
$$

where $e$ is the cake porosity. This expression has limited use in determining the pressure drop as a function of mass loading as it requires the knowledge of cake porosity which is often difficuit to estimate theoretically or measure experimentally due to the complexities and fragility of the cake structure. 


\section{CHAPTER 3}

\section{EXPERIMENTAL}

\subsection{Experimental Apparatus}

A schematic representation of the experimental set-up used for measuring pressure drop variation with mass loading at different relative humidities is shown in Figure 3.1. An identical experimental set-up, except for the aerosol generation techniques, was used for the two tests materials (hygroscopic and non-hygroscopic). The schematic diagrams of the aerosol generation techniques used in the tests are shown in Figure 3.2. The materials and equipments used in the experiments are listed in Table 3.1.

\subsubsection{Aluminum Oxide Aerosol Dispersion}

A Wright Dust Feeder (WDF) was used for dispersing non-hygroscopic aluminum oxide powders. The WDF was operated at 5-10 psig pressure range, resulting in an aerosol flow rate of $14 \mathrm{lpm}$ to $16 \mathrm{lpm}$. Only $3.0 \mathrm{lpm}$ of the aerosol was required for loading the filters. The remaining aerosol flow was filtered and then exhausted to the laboratory environment (Figure 3.2). 


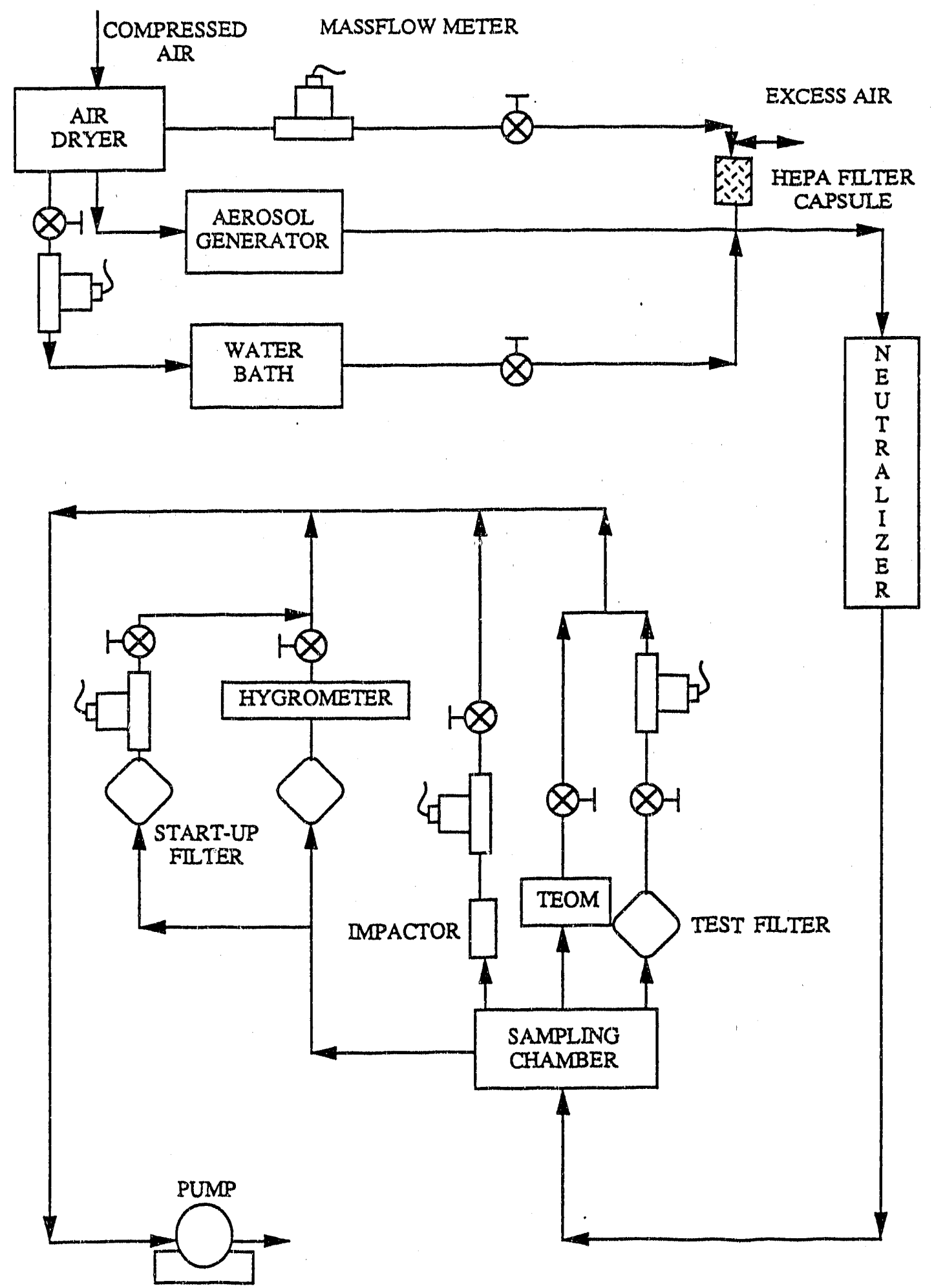

Figure 1 Schematic of the experimental system to measure pressure drop as a function of mass loading of hygroscopic and non-hygroscopic aerosols at different humidities. 


\subsubsection{Sodium Chloride Aerosol Generation}

The smaller $(M M D=0.5 \mu \mathrm{m}) \mathrm{NaCl}$ particles were generated by atomizing a $1 \%$ (Weight/volume) aqueous solution of $\mathrm{NaCl}$ in a TSI (Thermo-Sysytems Inc.) atomizer model 3076. The atomizer was operated at 35 psig resulting in an output aerosol flowrate of approximately $3.5 \mathrm{lpm}$. The larger $(M M D=1.0 \mu \mathrm{m}) \mathrm{NaCl}$ particles were generated by a 3-jet Collison nebulizer from a $5 \%$ (weight/volume) solution of $\mathrm{NaCl}$ in water. The 3-Jet Collison was operated at $20 \mathrm{psig.} \mathrm{At} \mathrm{this} \mathrm{pressure,} \mathrm{an} \mathrm{output} \mathrm{aerosol}$ flow rate of approximately $3.0 \mathrm{lpm}$ was produced. In both cases the entire output of aerosol was used for loading the filters. The high pressure air, used for atomizing, was pre-filtered and dried to a relative humidity of $<1 \%$ by a air dryer (Balston, Model $75-20$ ). Atomized liquid aerosol droplets $(\mathrm{NaCl})$ were pas sed through three diffusion dryers, in series, to yield a solid and dry test aerosol of $\mathrm{NaCl}$ (Figure 3.2). A multiple drying system was bound to be necessary for complete drying of the $\mathrm{NaCl}$ particles which show significant hysteresis in the drying and wetting cycle (Tang et al., 1977).

\subsubsection{Humidification}

The desired relative humidity $(\mathrm{RH})$ of the test aerosol was altained by mixing it with a humidified air strearn. The humidified air stream was obtained by bubbling particle free dry air through a heated water bath. The water bath temperature could be maintained within $\pm 1^{\circ} \mathrm{F}$ of the set temperature, hence, stable humidity levels were achievable. Any desired changes in the RH could be made by adjusting the water bath temperature or the humidified air flow rate. Typically, the flow rate of the humidifying air stream was 0.75 $\mathrm{lpm}$. This was mixed with 3.0 to $3.5 \mathrm{lpm}$ aerosol stream and approximately 2.0 to $2.5 \mathrm{lpm}$ 


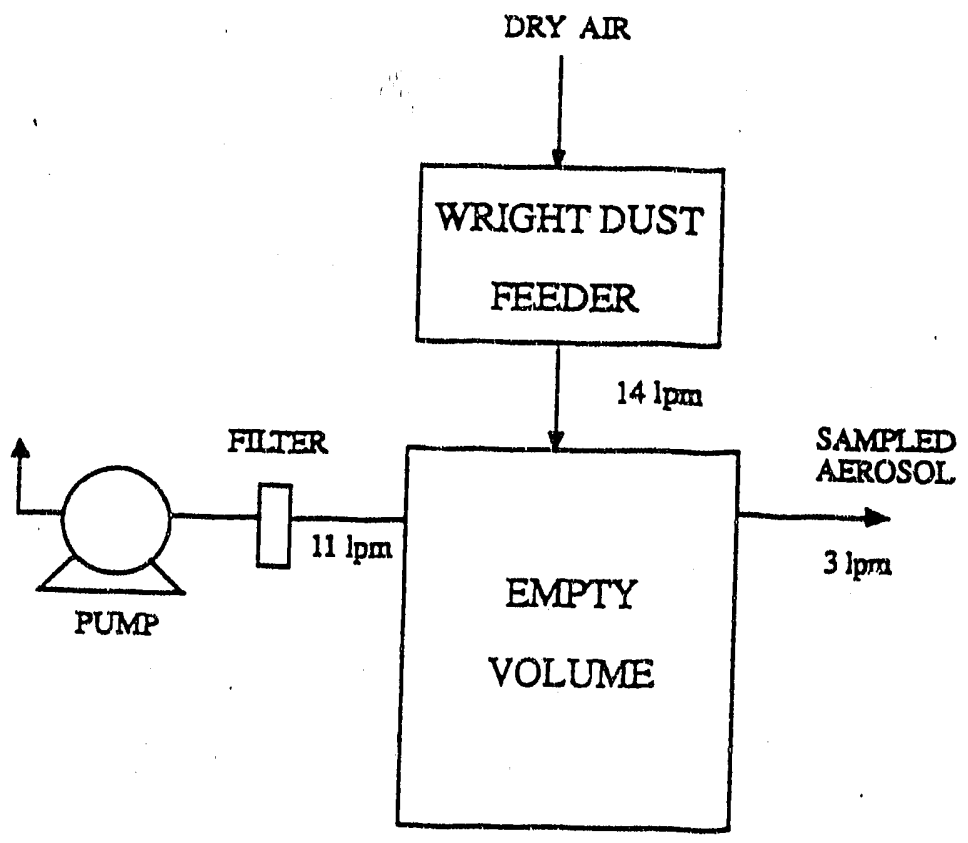

Aluminum oxide dispersion

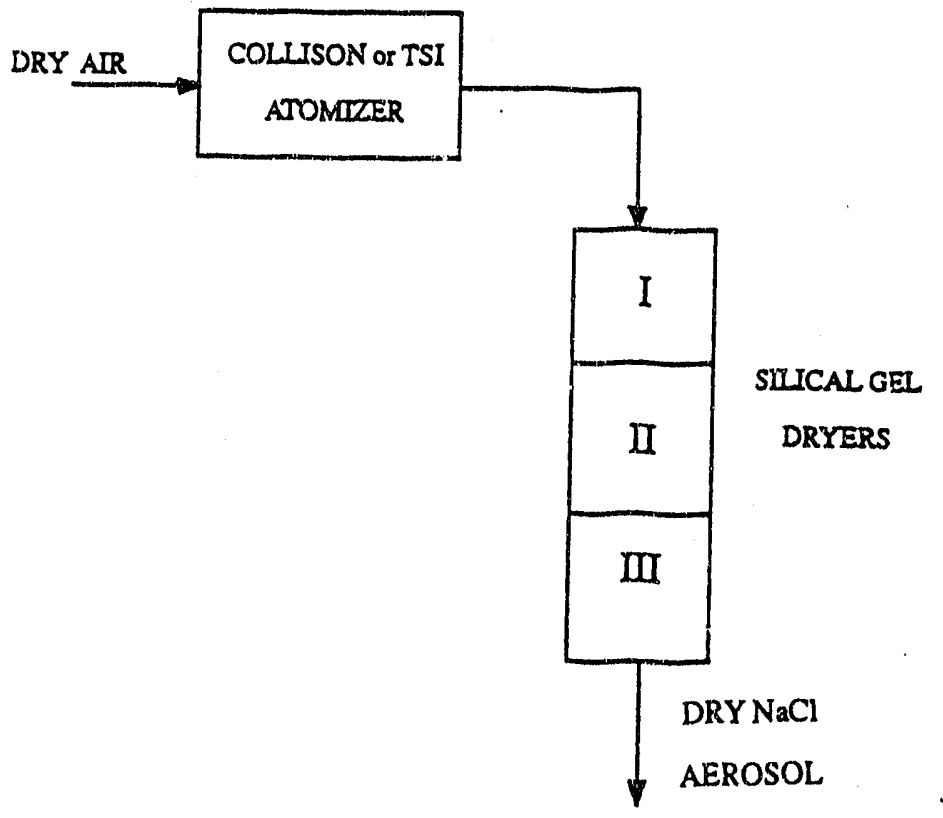

Sodium chloride generation

Figure 3.2 : Schematic of the aerosol generation systern used for generating aluminum oxide and sodium chloride aerosols 
of self adjusting bypass flow (Figure 3.1). This helped in maintaining at total flow of 6.2 Ipm to the sampling chamber during all stages of an experiment. Any change in the humidifled air flow rate caused a corresponding change in the bypasis air, thereby altering the ratio of dry air to the humidified air. By doing so fine adjustment in RH could be made which was particularly useful in offsetting the minor humidity changes due to arnblent temperature varlations or changes in dryer effectiveness over the duration of an experiment. With these controls, the relative humidity could be maintained within $\pm 3.0 \%$ of the desired value (Appendix-III).

\subsubsection{Neutralization}

Freshly gonerated aerosol particles always have associated electrostatic charge. Presence of charge on the particles can influence the pressure dresp across a filter. To reduce the electrostatic charge associated with the aerosol particles to a Boltzman equilibrium level, the aerosol/water vapor mixture was passed through a neutralizer (TSI, Model 3077).

\subsubsection{Aarosol Sampling}

After neutralization, the humidifled aerosol stream was inlet to the sampling chamber to which three identical aerosol sampling probos were attached (Figure 3.3). Each probe was made out of a $10 \mathrm{~cm}$ long $1 / 4^{\prime \prime}$ metal tube. The sampling end of each proba was shaped to simulate a thin walled sampling tube. Each probe was inserted through a drilled $1 / 4$ "swagelok-plpe union, screwed at the top of the sampling chamber, to sample the aerosol. This was done to prevent obstructions due to variations in the in the internal dlameter of the sampling probe. As shown in Figure 3.3, to these probes were 
connected a $47 \mathrm{~mm}$ filter holder, a Tapered Element Oscillating Microbalance (TEOM), and a cascade impactor (Intox Products, Model 5B). All these devices were mounted in an upside-down configuration such that they sampled aerosol against gravity. Initial experiments indicated that gravity aided sampling resulted in the formation of non-uniform cakes, especially on the $47 \mathrm{~mm}$ filter. These filters were observed to have a plie of particles at the center of the filter. It was found that particle agglomerates when sampled in the diection of gravity were leaving the diverging flow streamlines inside the filter holders and were getting deposited in the center of the filters in the form of a conical pile. However, by connecting the three devices in an inverted position, the tendency of pile formation was reduced considerably because the particles agglomerates were unable to gain sufficient inertia to be able to leave the flow streamlines. The sampling characteristics of the sampling system in the inverted configuration is presented in Appendlix-V.

\subsubsection{Data Collection}

The modiffed TEOM used in the present study had the ability to measure mass loading and pressure drop across the filter in real time. Figure 3.4 presents the essential features of a TEOM schematically. As shown in Figure 3.4, a TEOM filter is seated at the top end of the oscillating glass element. The test aerosol is pulled into the TEOM by a vacuum pump located outside the TEOM. The particles trapped on the filter increase the mass of the uscillating systern (stem and filter) thereby altering the reference oscillation frequency of the stem. The ascillating frequency of the stem is continuously monitored by a photo-sensor. Repeated shadowing of the photo-sensor by the stem results in an effective alternate current. The generated current is then ampiffled and compared with 


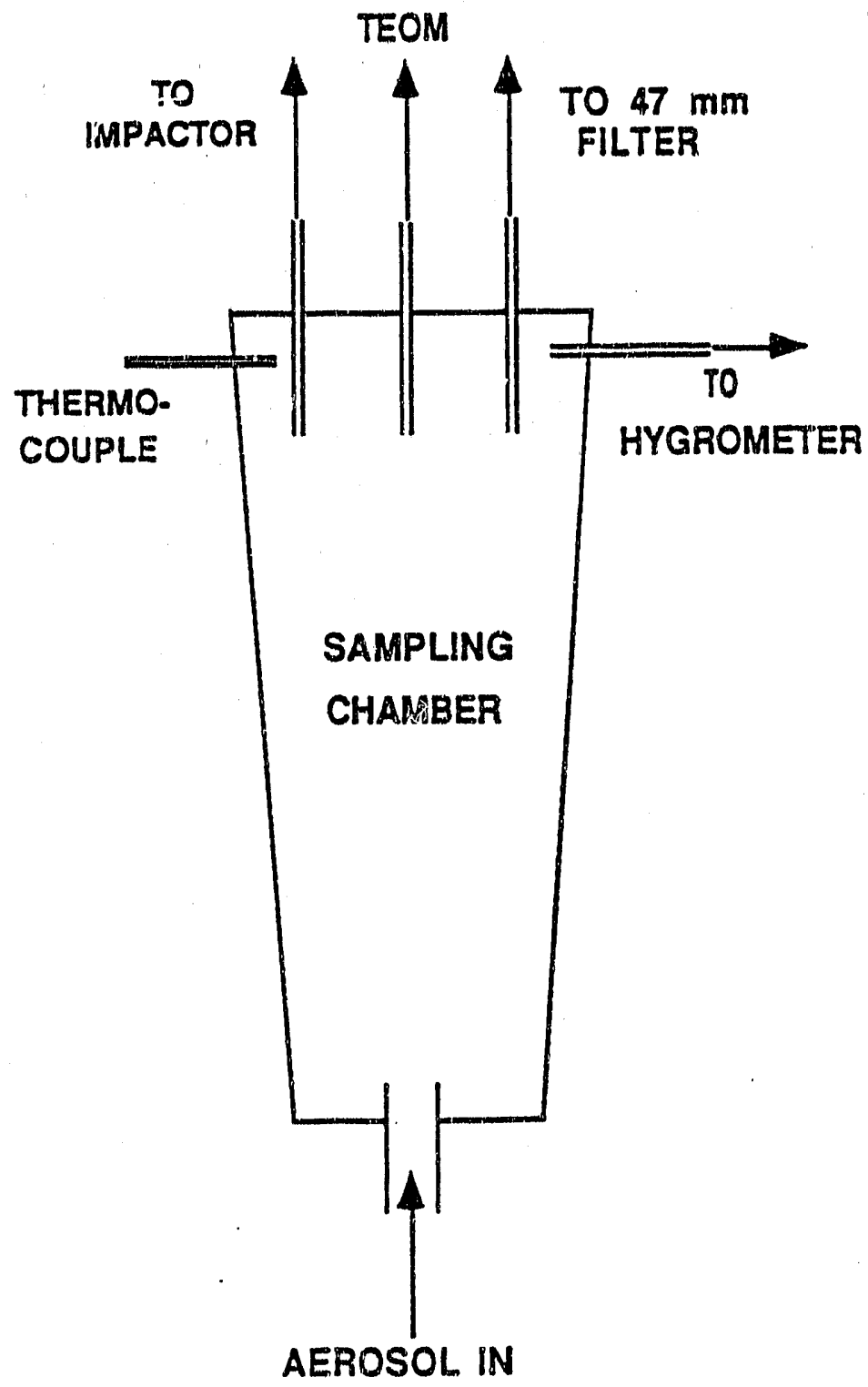

Figure 3.3: Schematic of the aerosol sampling system. 
the frequency of a reference quartz crystal. The direct proportionality between the frequency and the oscillating mass pre-calibrated such that the new frequency of the stem is converted to the total mass of the filter. The concomitant increase in the pressure drop across the filter due to particle deposition is monitored by a pressure transducer (Appendix-IV). The aerosol flow through the device is controlled and held constant by a massflow controller (Tylan, Model 260C). In the present study, the flow through the TEOM was controlled by metering valve located outside the unit. The :netering valve valve was adjusted using an electronic flow calibrator (bubble meter) such that the TEOM filter face velocity of the TEOM filter was $3.00 \mathrm{~cm} / \mathrm{s}$. The instantaneous values of the total mass of the filter $(\mathrm{g})$, the pressure drop (inch water), along with the values of aerosol flow $(\mathrm{lpm})$, the rate of mass collection $\left(\mathrm{g} \mathrm{s}^{-4}\right)$, the mass concentration $(\mathrm{g} / \mathrm{cc})$, are all recorded and displayed on a personal computer. The stored data is accessible for later analysis and re-plotting. The confidence test results for the mass loading and pressure difference across the TEOM filter with respect to two $47 \mathrm{~mm}$ filter holders are presented in Appendix-IV. One of these $47 \mathrm{~mm}$ filter holder was used to simultaneously sample all all test aerosols to verify the test end points (particles per unit filtration area and the specific cake resistance) of the TEOM filter data. The HEPA filter media was identical for both the $47 \mathrm{~mm}$ filter sampler and the TEOM and they sampled aerosol from two ports attached to the sampling chamber.

\subsubsection{Particle Size Measurements}

Studies by Biswas et al. (1987) observed that many particle size distribution measuring devices tend to be biased while sampling humid aerosols. In their paper they discuss the effect of humidity on the accuracy of Optical Particle Counter (OPC) and 

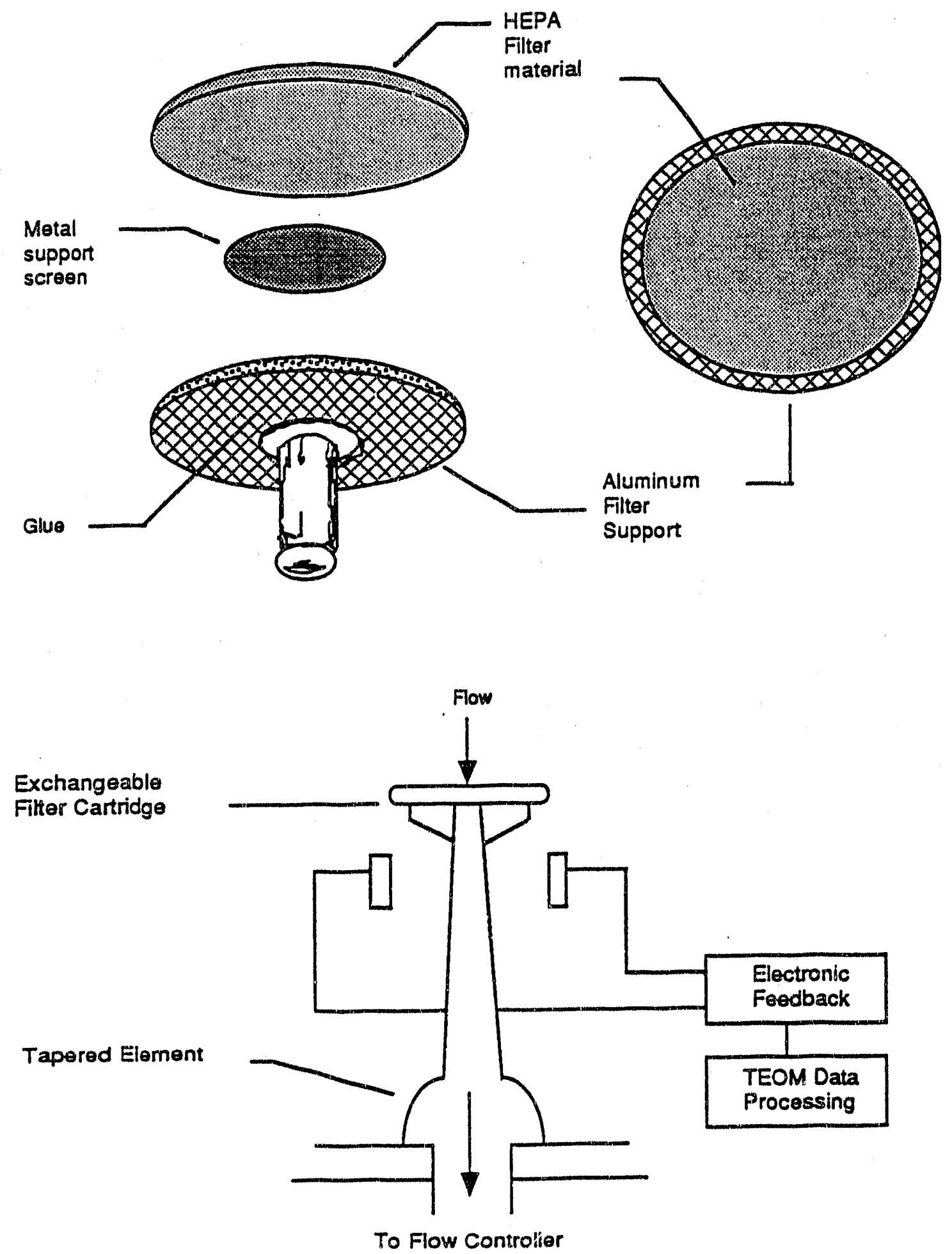

Figure 3.4 : Design of a TEOM Filter and the TEOM Oscillating Element. 
cascade impactor.

In an OPC the sampled gas stream is mixed with the recirculating gas causing a change in the humidity of the gas at the point of measurement. Consequently, the moisture associated with the particles establishes a new equilibrium with the new ambient conditions. In the case of hygroscopic particles this loss of moisture will eventually cause a change in the particles size. The error in particle size measurement was siginificant at humidity levels of $80 \%$ and beyond. It was reportewd that, to be able to measure particle size with reasonable accuracy at such humidity levels the instrument had to be running for 8 to 9 hours prior to measurements so that the recirculating gas could equilibrate with the inlet gas. This additional operating time period was not practical for these mass loading experiments.

Contrary to an OPC, in an impactor, repeated expansion of the inlet gas stream through the jets causes a decrease in gas temperature and pressure progressively. with each stage causing water vapor to condense, especially under high humidity conditions. The study, however, reported that if the Mach Number in all the stages can be maintained below 0.005 , the bias in particle size measurements due to condensed water droplets would be minimal even at relative humidities exceeding $90 \%$. Keeping this in mind a brief study was carried out to select proper impactor.

The impactor used in the present study sampled aerosol at a flow rate of $5 \mathrm{lpm}$, and had a maximum Mach number of 0.004 (Appendix-VI). Therefore, even under high humicity conditions (>90\%), the bias in the size distribution was considered negligible. 
The size measurements were done at the end of each run. A sampling time of 3 to 4 minutes was found to be necessary for the sufficient loading on the impactor substrates. An analytical mass balance (Mettler, Model Gram-Attic) with a resolution of atleast $10^{-4}$ $\mathrm{g}$ or $0.01 \mathrm{mg}$ was used for weighing the impactor substrate mass. From these measurements the Mass Median Aerodynamic Diameter (MMAD) and the Geometric Standard Deviation (GSD) of the aerosol was computed. To be able to use the theoretical expression developed earlier (Chapter 2), the MMAD was converted to Mass Median Diameter (MMD) (Appendix-VII) and then to Geometric Mean Diameter.

\subsubsection{Relative Humidity Measurement}

As shown in Figure 3.3, a portion of the humidified aerosol was sampled from the top of the sampling chamber. The sampled aerosol was filtered before inletting into the hygrometer sensor to prevent the fouling of the hygrometer (General Eastern, model M2 with sensor $1111 \mathrm{H}$ ). The metal tube transporting the sample was heated to prevent loss of water vapor due to condensation. By preveriting loss of water vapor and by measuring the gas temperature inside the sampling chamber, the sampling chamber relative humidity was accurately measured by the hygrometer located outside the sampling chamber.

\subsection{Design of Experiments}

In the present study sodium chloride $(\mathrm{NaCl})$ and aluminu" oxide $\left(\mathrm{Al}_{2} \mathrm{O}_{3}\right)$ were used for the hygroscopic and the non-hygroscopic mass loading tests. Sodium Chloride was used for the hygroscopic studies because its hygroscopic properties are well characterized (Appendix-II), it is easy to generate and is non-toxic. Choice of Aluminum 
oxide powder $\left(\mathrm{Al}_{2} \mathrm{O}_{3}\right)$ as the non-hygroscopic test aerosol was based on the fact that it is a metal oxide and somewhat similar to the oxides which result from a possible accident scenario (Cuddihy et al., 1989). For a reasonable comparison between the hygroscopic and the non-hygroscopic test results, experiments were performed over a wide range of humidities (Table 3.2).

The lowest achievable humidity, for the duration of an experiment (ap proximately 6 hrs), for $\mathrm{NaCl}$ aerosol was determined to be $35 \% \mathrm{RH}$. This value was obtained by aerosolizing pure water with a Collison nebulizer and recording the humidity with a strip chart recorder. From an initial humidity of about $1 \%$, the relative humidity increased to $20 \%$ in the first 5 minutes of the experiment. Subsequent increase in the humidity was gradual took approximately 4 hours to reach a value of $30 \%$. Since an experiment was expected to run for about 6 hours, it was safe to fix the base line humidity at $35 \%$ for $\mathrm{NaCl}$ aerosol. The solid $\mathrm{NaCl}$ aerosol deliquesces and turns liciuid at a relative humidity 
Table 3.1 : Equipment and Materials used in the Experiments

Equipment/Material

Dry Air Supply

Flow Meter

Flow Controllers

Collison Aerosol Generator

TSI Aerosol Generator

Wright Dust Feeder

Neutralizer

$47 \mathrm{~mm}$ Filter Holders

TEOM

Impactor

Hygrometer

RH Sensor
Manufácturer

Model

Balston

Aalborg

Tylan

BGI

TSI

BGI

WDF-II

TSI

3077

Intox Products

Rupperecht \& Patashnick

Intox Products

$5 B$

General Eastern

Hygro-M2

General Eastern 
of approximately $75 \%$. Therefore, tests were carried out at humidity conditions both below and above the deliquescent point (Table 3.2).

Two particle size distributions, nominally with mass median diameters (MMD) of 0.5 $\mu \mathrm{m}$ and $1 \mu \mathrm{m}$ were tested to determine the effect of particle size. The choice of particle size was such that it represents possible particle sizes predicted by the experiments designed to simulate certain nuclear accidents (Buckle, 1991).

Temperatures and pressures were maintained at the ambient laboratory conditions. The filtration velocity was $3.00 \mathrm{~cm} / \mathrm{s}$ at which most HEPA filters are tested. Table 3.2 lists the experimental conditions.

Table 3.2 : Experimental conditions for the non-hygroscopic aluminum oxilye and the hygroscopic sodium chloride test aerosols.

\begin{tabular}{|c|c|c||}
\hline Test Aerosol & $\begin{array}{c}\text { Non-hygroscopic } \\
\text { Aluminum oxide }\end{array}$ & $\begin{array}{c}\text { Hygroscopic } \\
\text { Sodium Chloride }\end{array}$ \\
\hline Particle Size & Table 4.2 & Table 4.3 \\
\hline $\begin{array}{c}\text { Relative } \\
\text { Humidity }(\mathrm{RH})\end{array}$ & $\begin{array}{c}1 \%, 35 \%, 80 \%, 90 \% \text { and } \\
100 \%\end{array}$ & $\begin{array}{c}35 \%, 55 \%, 65 \%, 80 \% \text { and } \\
90 \%\end{array}$ \\
\hline $\begin{array}{c}\text { Filtration } \\
\text { Velocity }\end{array}$ & $3.00 \mathrm{~cm} \mathrm{~s}^{-1}$ \\
\hline Temperature & $\left(25^{\circ} \mathrm{C}\right)$ \\
\hline Pressure & $(1 \mathrm{~atm})$ \\
\hline
\end{tabular}




\subsection{Estimation of Theoretical $R$}

To use the Rudnick-Happel expression (Chapter 2) for calculating theoretical R, values of cake porosity are required. These porosity values were calculated indirectly by first estimating the cake density

$$
\text { Cake density }=\text { cake mass } / \text { cake volume }
$$

To determine the cake thickness, a movable microscope, fitted with a micrometer, was focussed on the bare $47 \mathrm{~mm}$ filter surface and then on the center of the cake. The difference between the two readings is the local cake thickness. Ten cake thickness measurements were made at different cake locations to compute a statistically reliable average thickness. Any data point which was more than twice the standard deviation away from the average was discarded and a new average was calculate without it. Three such observations in three different data sets were discarded. Knowing the average cake thickness, the cake volume was computed using the cake diameter. The mass of the particles in the cake was determined gravimetrically. The ratio of the mass to the cake volume yielded an average cake density. The ratio of the cake density to the dry particle density is then subtracted from unity to determine the value of cake porosity.

$$
e=1-\left(\rho_{\text {cake }} / \rho_{\mathrm{p}}\right)
$$

The data used for computing cake porosities are presented in Appendix-VIII for aluminum oxide and $\mathrm{NaCl}$ respectively. 


\section{CHAPTER 4}

\section{RESULTS AND DISCUSSION}

\subsection{Effect of Humidity on Clean HEPA Fịlter}

The glass fiber HEPA filter material used in the present study was pre-treated with a hydrophobic compound. Initial tests performed to determine the effect of humidity on the clean filter pressure drop, $\Delta P_{\text {fiter }}$ indicated that $\Delta P_{\text {fltor }}$ remained constant for relative humidity changes in the range of $1 \%$ to $100 \%$. These tests like all other tests were conducted at a constant filtration velocity of $3.00 \mathrm{~cm} \mathrm{~s}^{-1}$. The values of $K_{1}$ calculated from the initial pressure drop data are presented in the Table 4.1 for all the cases investigated.

Table 4.1 clearly indicates that the variation in $K_{1}$ is minimal even at $100 \%$ humidity. To determine the long term effects of water vapor on $K_{1}$, the TEOM filter was subjected to particle free air at $100 \% \mathrm{RH}$. The experiment was carried out for 2 hours and 19 minutes. During this time period the TEOM did not record any steady increase in mass. The change in the collected mass fluctuated in both increasing and decreasing directions and could be attributed to the minor variations in the oscillation frequency of the stem. The pressure drop also fluctuated around the initially observed value. Visual examination of the TEOM filter under a magnifying glass did not exhibit any liquid on the filter surface indicating the absence of condensed water. Subsequent overnight drying of the filter in 
an oven at $105^{\circ} \mathrm{C}$ also did not show any loss in mass. All these tests confirmed that $K_{1}$ remains constant even at $100 \% \mathrm{RH}$, therefore, no correction was required for the calculation of $K_{2}$ from the pressure increase versus mass loading data.

Table 4.1 : Variation of Clean Filter Resistance with Humidity

\begin{tabular}{|c|c|c|c|}
\hline $\begin{array}{c}\text { Humidity } \\
\text { (\%) }\end{array}$ & $\begin{array}{l}\Delta \mathrm{P}_{0} \\
(\mathrm{~Pa})\end{array}$ & $\begin{array}{l}\text { Velocity } \\
\left(\mathrm{cm} \mathrm{s}^{-1}\right)\end{array}$ & $\begin{array}{l}K \\
\left(s^{-1}\right) \\
\end{array}$ \\
\hline 1 & 245 & 2.96 & 0.33 \\
\hline 1 & 300 & 3.01 & 0.40 \\
\hline 35 & 260 & 3.00 & 0.35 \\
\hline 35 & 317 & 3.07 & 0.41 \\
\hline 55 & 220 & 3.01 & 0.29 \\
\hline 55 & 272 & 3.03 & 0.36 \\
\hline 80 & 260 & 2.96 & 0.35 \\
\hline 80 & 225 & 3.00 & 0.30 \\
\hline 90 & 260 & 3.05 & 0.34 \\
\hline 90 & 260 & 3.02 & 0.34 \\
\hline 100 & 252 & 3.00 & 0.34 \\
\hline 100 & 260 & 2.98 & 0.35 \\
\hline \multicolumn{4}{|c|}{$\begin{array}{r}\qquad\left(K_{1}\right)_{a v}=0.347\left(\mathrm{~s}^{-1}\right) \\
\sigma_{x}= \pm 0.033 \\
\text { Coefficient of variation }= \pm 9.5 \%\end{array}$} \\
\hline
\end{tabular}

\subsection{Results of Non-Hygroscopic Tests}

The non-hygroscopic mass loading tests used two sizes of aluminum oxide particles to challenge the TEOM and the $47 \mathrm{~mm}$ HEPA filters at various humidities. The MMD's of the two powders, as specified by the manufacturer, were $1.19 \mu \mathrm{m}$ and $0.45 \mu \mathrm{m}$. The MMDs calculated from the measured MMADs are is given in Table 4.2. A particle density 
of $3.9 \mathrm{~g} / \mathrm{cm}^{3}$ was used for these calculations (Appendix-VII).

At the start of the experiment the aerosol was passed through a start-up filter until a stable humidity was attained in the system (Figure 3.1). Then the start-up filter was shut off and the aerosol was directed to the TEOM and $47 \mathrm{~mm}$ filters. The pressure drop across the TEOM filter and the mass collscted on the filter as a function of time were recorded. This data combined with the knowledge of filter area allowed the pressure drop versus areal loading density (mass loading per unit filtration area) ware plotted for each test. Except for the hygroscopic tests above the deliquescent point, these plots were linear. The slope of these plots was ther, divided by the filter face velocity (equation 2.4) to compute the experimental value of the specific cake resistance for each test.

For the larger $(1.0 \mu \mathrm{m}$ nominal $M M D)$ aluminum oxide particles, the decrease in $K_{2}$ is observed at all humidities (Table 4.2 \& Figure 4.2). Qualitatively, this effect can be attributed to an increase in the particle to particle adhesive forces as the humidity is increased. The magnitude of these forces is dependent on several factors such as the nature of the particle material (here hygroscopicity), its size and shape, surface roughness and the relative humidity of the surrounding gas (Zimon, 1969). Therefore, at high humidities, the particles are expected to have higher adhesive forces effecting firmer bonding between themselves. Consequently, during cake formation, the particles tend to stick to the particles already present on the cake surface rather than rolling into and filling the interstitial spaces. This pattern of deposition is expected to form a cake comprising of chain like particle structures with relatively straight channels between them. When compared to the cake with a random network of particles, the cake formed at high humidity will offer less resistance to the flow due to the "straightness" of the channels and 
consequently more mass can be loaded to attain a given pressure drop. Similar observations of reduction in the pressure drop with increase in hurnidity have been made by Durham and Harrington (1971) and Ariman and Helfritch (1977) for non-hygroscopic dusts.

It was seen that for the smaller $\left(0.5 \mu \mathrm{m}\right.$ nominal MMD) aluminum oxide particles $\mathrm{K}_{2}$ did not vary significantly until a RH of $90 \%$, however, above $90 \%$ RH the decrease in $\mathrm{K}_{2}$ was significant (Table 4.2 \& Figure 4.1). This decrease in $K_{2}$ could be due increased particle to particle adhesion caused by presence of minute quantities of condensed water on the surface. However, more work, taking into account the particle morphology and all the other factors influencing the forces between the particles, needs to be done in order to describe the behavior below $90 \% \mathrm{RH}$.

The variation in the porosities estimated by the procedure outlined earlier (Chapter 3) was random and could not be attributed to the changes in RH. Most llkely, these variations were caused by the errors associated with the cake thickness measurements. The coefficient of variation (COM of local cake thickness varied from 5.1 to $37.3 \%$ (average $\mathrm{COV}=2.0 .6 \%$ ) for the aluminum oxide particle cakes. This caused a deviation of 1.5 to $8.4 \%$ in the porosity estimates (Table 4.2$)$. The experimental $R\left(R_{c}=K_{2} / K_{2 c}\right.$ and $R_{s}=K_{2} / K_{2 \text { stakes }}$ ) values and the theoretical values calculated from the Rudnick-Happel expression (equation 17) using the estimated porosity values are compared in Figure 4.3 for the aluminum oxide. The $R_{c}$ values (exc(pt for one point) are in reasonable agreement with the theoretically determined $R$ values (equation 2.17 ) indicating that for the lognormally distributed aerosols the developed expression (equation 2.13 ) is accurate in determining the specilic cake resistance. 


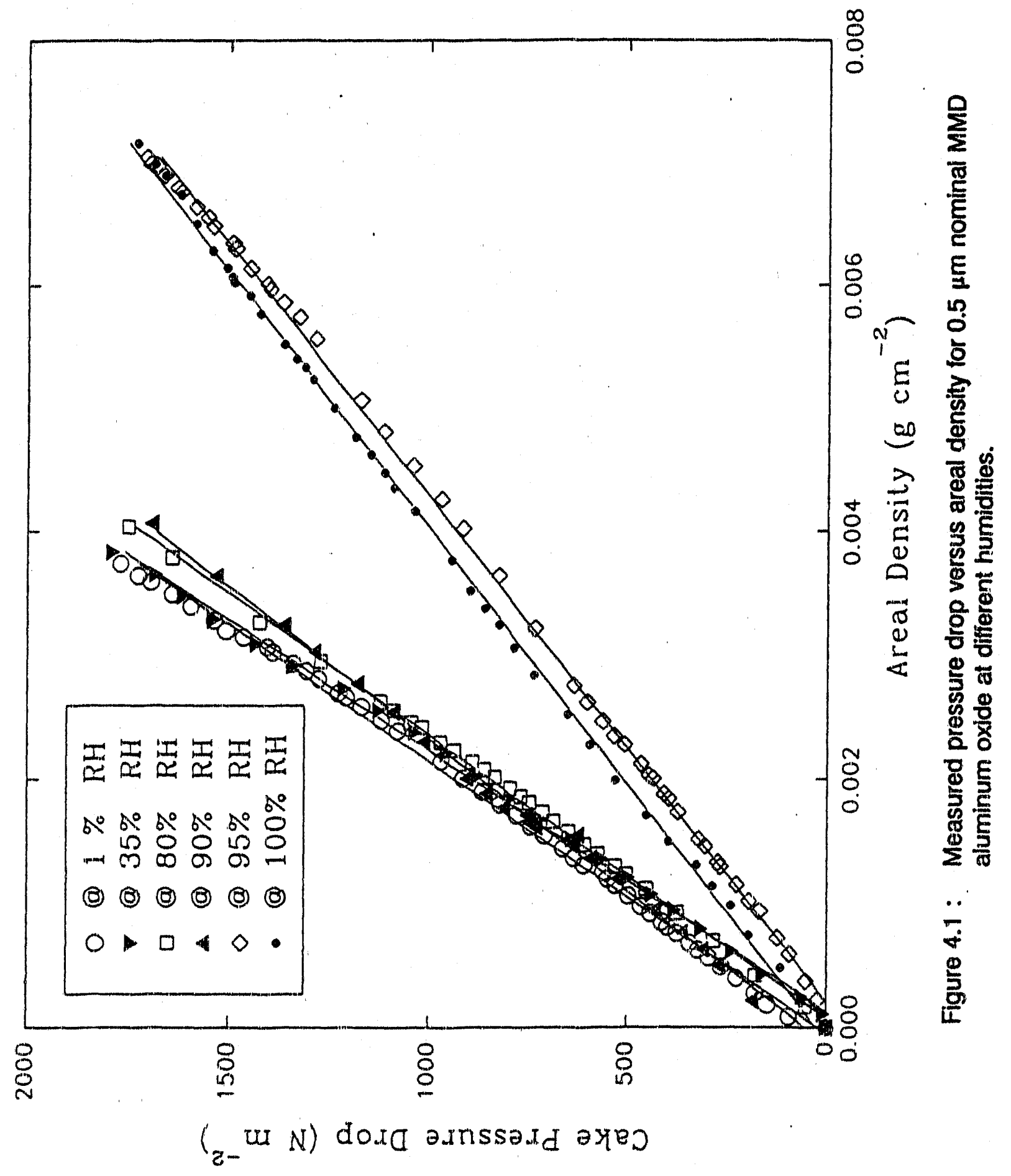




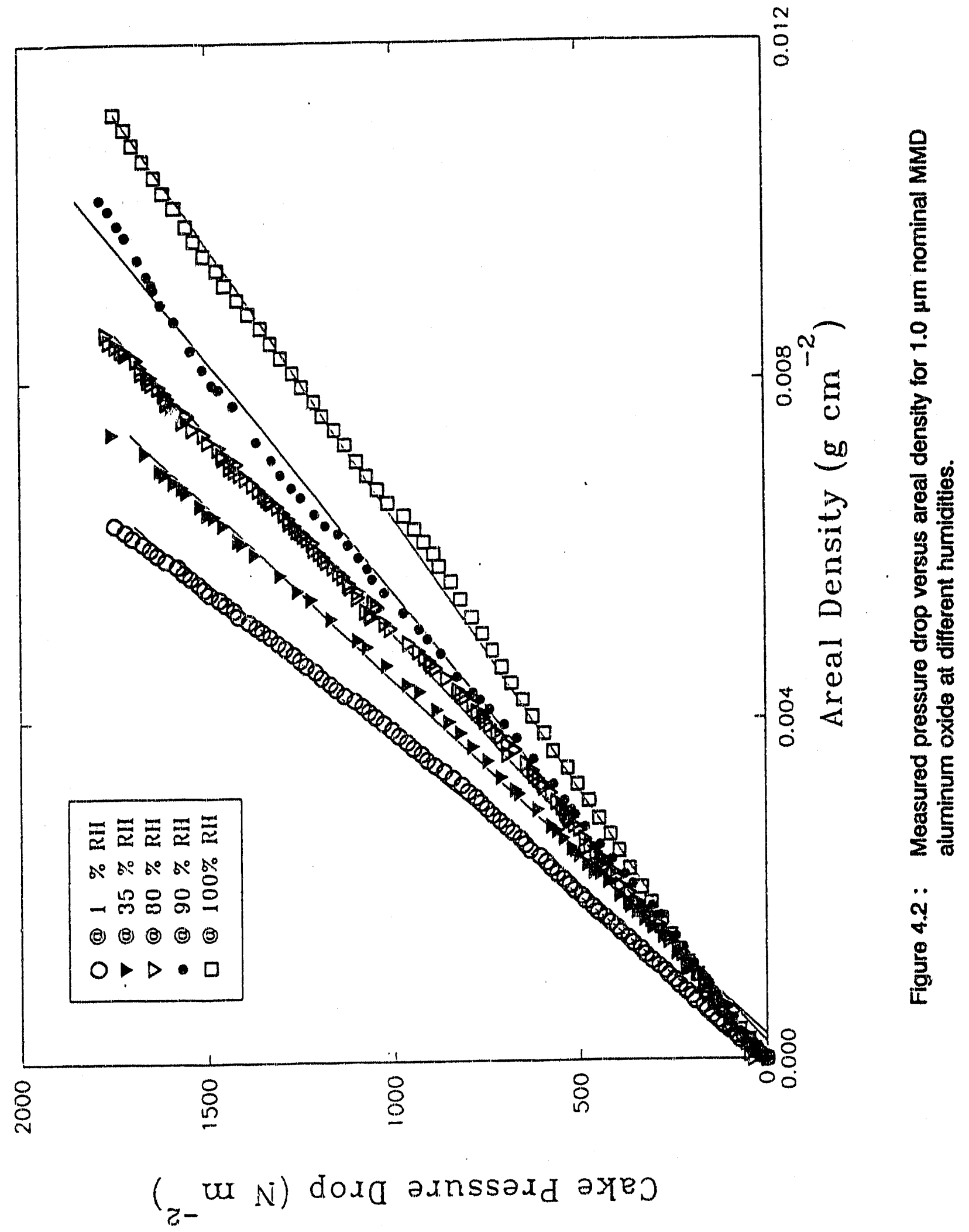


Table 4.2 : Measured particles size, geometric standard deviation, specific cake resistance and resistance factors for aluminum oxide test aerosol.

\begin{tabular}{|c|c|c|c|c|c|c|c|c|}
\hline $\begin{array}{l}\text { RH } \\
(\%)\end{array}$ & $\begin{array}{l}d_{m m} \\
(\mu \mathrm{m})\end{array}$ & $\sigma_{8}$ & $\begin{array}{c}K_{2} \\
\left(s^{-1}\right)\end{array}$ & $\begin{array}{c}K_{\text {zstokes }} \\
\left(8^{-1}\right)\end{array}$ & $\mathbf{R}_{\mathbf{s}}$ & $\begin{array}{l}K_{2 c} \\
\left(8^{-1}\right)\end{array}$ & $\begin{array}{l}\text { exstd. } \\
\text { dev }\end{array}$ & $\mathbf{R}_{\mathbf{c}}$ \\
\hline \multicolumn{9}{|c|}{$0.5 \mu \mathrm{m}$ nominal MMD Aluminum Oxide } \\
\hline 1 & 0.54 & 1.73 & 1510000 & 219781 & 6.9 & 546519 & $0.85 \pm 0.01$ & 2.8 \\
\hline 1 & 0.62 & 1.66 & 1592500 & 171931 & 9.3 & 410073 & $0.94 \pm 0.01$ & 3.9 \\
\hline 35 & 0.53 & 1.73 & 1600000 & 227118 & 7.0 & 561753 & $0.92 \pm 0.01$ & 2.8 \\
\hline 35 & 0.57 & 1.68 & 1737500 & 199718 & 8.7 & 478001 & $0.93 \pm 0.02$ & 3.6 \\
\hline 80 & 0.65 & 1.64 & $1472500^{\circ}$ & 157961 & 8.3 & 371287 & $0.94 \pm 0.01$ & 3.8 \\
\hline$\infty 0$ & 0.69 & 2.20 & 1352500 & 141841 & 9.5 & 532684 & - & 2.5 \\
\hline 85 & 0.75 & 1.80 & 820000 & 121931 & 6.7 & 359246 & $0.94 \pm 0.02$ & 2.3 \\
\hline 100 & 0.73 & 1.96 & 794750 & 128074 & 6.2 & 435201 & $0.90 \pm 0.01$ & 1.8 \\
\hline 100 & 0.63 & 1.58 & 720000 & 167074 & 4.3 & 361363 & - & 2.0 \\
\hline \multicolumn{9}{|c|}{$1.0 \mu \mathrm{m}$ nominal MMD Aluminum Oxide } \\
\hline 1 & 0.99 & 1.80 & 9182.50 & 73158 & 12.6 & 232157 & $0.86 \pm 0.03$ & 3.9 \\
\hline 35 & 1.33 & 1.48 & 839750 & 42059 & 20.0 & 81997 & $0.86 \pm 0.03$ & 10.2 \\
\hline 35 & 1.03 & 1.80 & 802500 & 67960 & 11.8 & 217722 & $0.83 \pm 0.06$ & 3.7 \\
\hline 80 & 1.07 & 2.06 & 705000 & 63298 & 11.1 & 2745000 & $0.87 \pm 0.03$ & 2.6 \\
\hline 90 & 1.12 & 1.61 & 606500 & 58117 & 10.4 & 142755 & $0.92 \pm 0.01$ & 4.2 \\
\hline 100 & 1.07 & 1.60 & 520000 & 63298 & 8.2 & 152200 & - & 3.4 \\
\hline 100 & 1.30 & 1.60 & 494250 & 42882 & 11.5 & 107938 & $0.84 \pm 0.02$ & 4.6 \\
\hline
\end{tabular}




\subsection{Hygroscopic Aerosols}

\subsubsection{Behavior of Hygroscopic Aerosols in Humid Environments}

The phase rule of physical chemistry states that the equilibrium of a system of $\mathrm{C}$ componerits and $P$ phases possesses $C \cdot P+2$ degrees of freedom. For a system of three phases consisting of a soluble salt, its aqueous solution and water vapor with two components - water and salt - the degrees of freedom are $2-3+2=1$, which means that if we specify one thermodynamic variable - temperature - the other variables must take on a prescribed value and are not free to vary. In other words at a given temperature, water vapor, solution and solid can exist only at one vapor pressure or relative humidity, which also implies a fixed composition for the liquid phase. This relative humidity therefore represents a phase transition point and is generally known as the deliquescent point. As reported by Tang et al., (1977) the deliquescent point for the pure $\mathrm{NaCl}$ particles is at $75 \% \mathrm{RH}$. Considering a solution drop, large enough that effects of curvature can be neglected, the concentration of soluble material in the solution determines its equilibrium relative humidity. If the $\mathrm{RH}$ in the environment is higher than equilibrium $\mathrm{RH}$, the drop will grow, displaying hygroscopic nature, and become more dilute. If the RH is lower, the drop will evaporate thereby increasing the solution concentration. Continued evaporation of the drop will result in solute crystallization and eventually a solid particle will be obtained. In the reverse phenomenon, a solid particle takes up moisture and eventually turns into a liquid drop in humid environments. In most cases the phase transition point is not identical for the drying and wetting cycle. This effect is commonly known as hysteresis. In the case of pure $\mathrm{NaCl}$ the crystallization occurs at $44 \% \mathrm{RH}$ (Tang et al., 1977). 


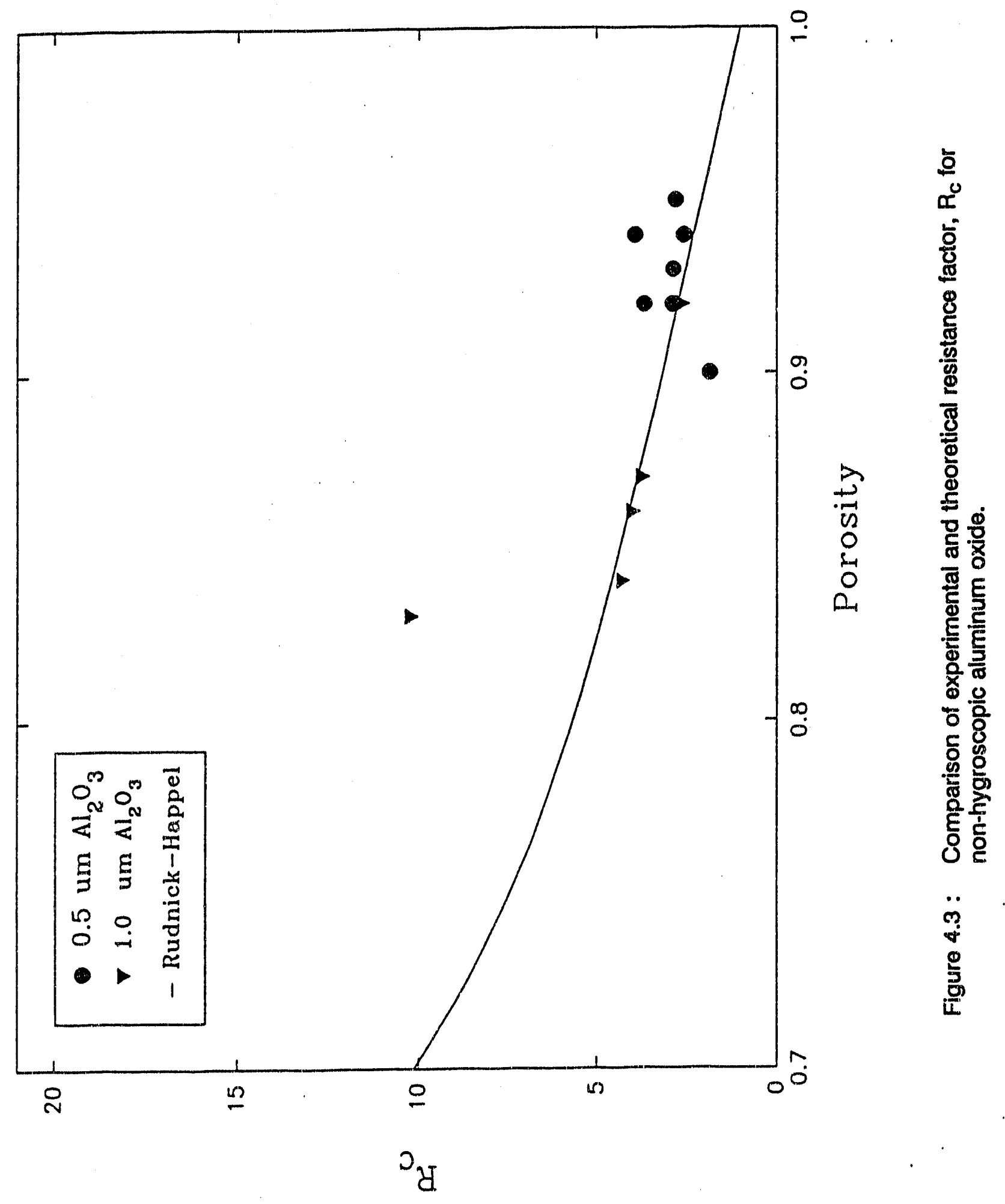




\subsubsection{Estimation of Equilibrium Contact Time for Sodium Chloride}

According to Tang et al. (1977) and Golli et al. (1974), submicron $\mathrm{NaCl}$ particles require approximately $2.0 \mathrm{sec}$ to reach equilibrium size at a given humidity. The contact time between the aerosol and the water vapor based on the total volume of the experimental apparatus and the volumetric flow rates was estimated to be around $11.0 \pm 2.0$ seconds. The contact time was also estimated by an independent method in which the humidifier was cut-off from the system after the humidity in the system had stabilized (Figure 3.1). At the same time a stop watch was started to note the time elapsed until thie hygrometer indicated a change. Typically, this time varied from 13.0 to 15.0 seconds. By subtracting the hygrometer response time (1.5 seconds) from this value the actual contact time of 11.5 to 13.5 seconds was obtained. It is clear from these estimates of contact time that for the given system the contact time was least five times the interval required to attain equilibrium.

\subsubsection{Results of Hygroscopic Tests Below Deliquescent Point}

The results of the mass loading experiments performed with a hygroscopic aerosol, $\mathrm{NaCl}$ are presented in Figures 4.4 to 4.10. For humidities less than the deliquescent point $(<75 \%)$, a linear relationship of pressure drop to rnass loading was obtained (Figures 4.4 and 4.5). As observed for the non-hygroscopic particles, the specific cake resistance, $K_{2}$, also decreases with an increase in humidity. The decrease in $K_{2}$, however, is greater compared to the similar size non-hygroscopic aluminum oxide particies. A possible reason for this may be the higher adhesiveness of the hygroscopic $\mathrm{NaCl}$ particles compared to the non-hygroscopic aluminum oxide particles at elevated humidities, thus leading to the formation of a more open cake structure. Higher particle 
adhesiveness of $\mathrm{NaCl}$ also caused the particles to stick together to form agglomerates indicated by the observed increase in the particle size (Table 4.3). A larger effective particle size due to coagulation also contributes to the decrease in $K_{2}$ as dictated by its inverse relationship to the square of particle size (equation 2.7 or 2.13). However, it should be noted that thermodynamically it is not possible for a $\mathrm{NaCl}$ particle to grow below the deliquescent point (Tang et al., 1977). As explained earlier (section 4.3.1), below the deliquescent point water exists only in vapor form in the system and can not contribute towards particles growth.

Similar to the non-hygroscopic aluminum oxide case, the variation in the estimated porosities was random and could not be attributed to the changes in RH (Table 4.3). However, the errors associated with the cake thickness measurements were higher than the aluminum oxide particulate cakes. The coefficient of variation (COV) of local cake thickness varied from 9.2 to $48.2 \%$ (average $\mathrm{COV}=31.2 \%$ ) leading to a variation of 2.5 to $33.3 \%$ in the porosity estimation (Table 4.3). As shown in Figure 4.6 the corresponding $R_{c}$ values were much lower than the theoretical $R$ calculated using equation (2.17). 
Table 4.3 : Measured particles size, geometric standard deviation, specific cake resistance and resistance factors for sodium chloride test aerosol.

\begin{tabular}{|c|c|c|c|c|c|c|c|c|}
\hline $\begin{array}{l}\mathrm{RH} \\
(\%)\end{array}$ & $\begin{array}{l}d_{m m} \\
(\mu m)\end{array}$ & $\sigma_{\mathfrak{g}}$ & $\begin{array}{l}K_{2} \\
\left(s^{-1}\right)\end{array}$ & $\begin{array}{c}K_{\text {2Slokes }} \\
\left(s^{-1}\right)\end{array}$ & $R_{S}$ & $\begin{array}{l}K_{2 c} \\
\left(s^{-1}\right)\end{array}$ & $\begin{array}{c}\text { exstd. } \\
\text { dev }\end{array}$ & $\mathrm{R}_{\mathrm{c}}$ \\
\hline \multicolumn{9}{|c|}{$0.5 \mu \mathrm{m}$ nominal $\mathrm{MMD} \mathrm{NaCl}$} \\
\hline 35 & 0.55 & 1.61 & 1741500 & 383434 & 4.6 & 465842 & $0.80 \pm 0.08$ & 3.7 \\
\hline 55 & 0.56 & 2.20 & 1097500 & 371405 & 3.0 & 684888 & $0.77 \pm 0.12$ & 1.6 \\
\hline 65 & 0.63 & 1.97 & 867000 & 301105 & 2.9 & 536675 & $0.60 \pm 0.20$ & 1.6 \\
\hline \multicolumn{9}{|c|}{$1.0 \mu \mathrm{m}$ nominal $\mathrm{MMD} \mathrm{NaCl}$} \\
\hline 35 & 1.21 & 1.95 & 571250 & 90596 & 6.3 & 203518 & $0.72 \pm 0.08$ & 2.8 \\
\hline 55 & 1.45 & 1.72 & 434500 & 64354 & 6.8 & 108271 & $0.64 \pm 0.06$ & 4.0 \\
\hline 67 & 2.12 & 2.20 & 380165 & 31101 & 12.2 & 113320 & $0.78 \pm 0.02$ & 3.4 \\
\hline
\end{tabular}




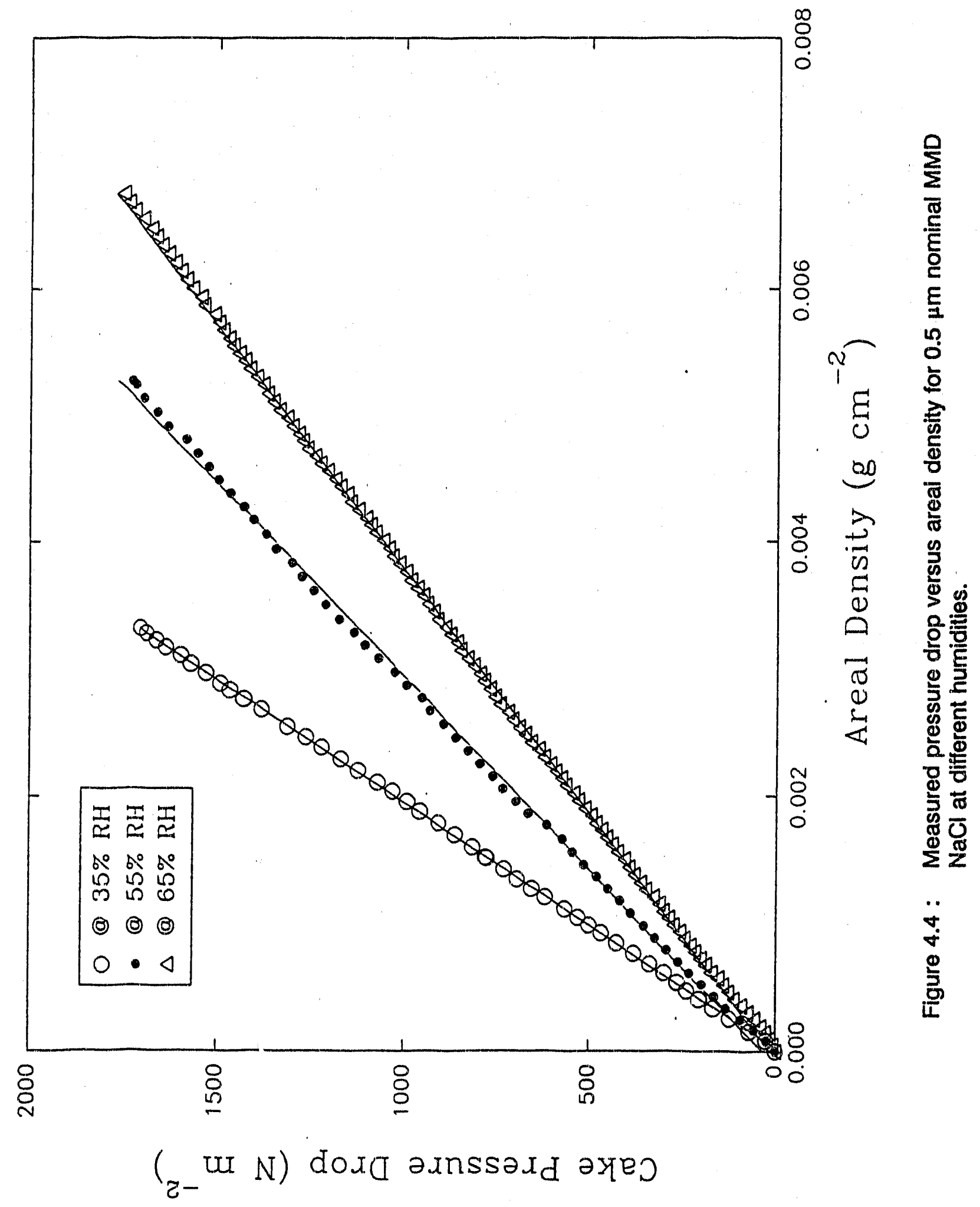




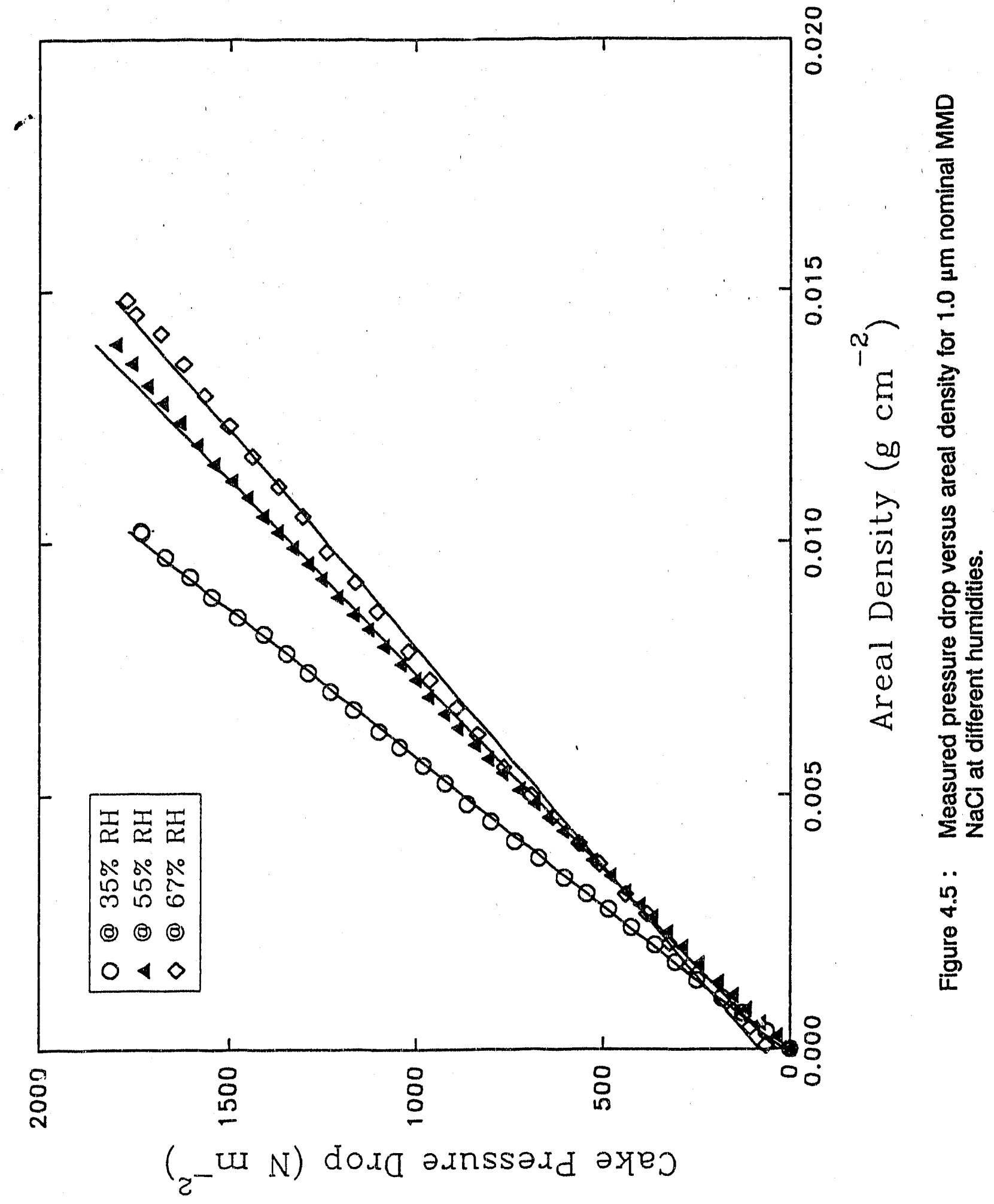




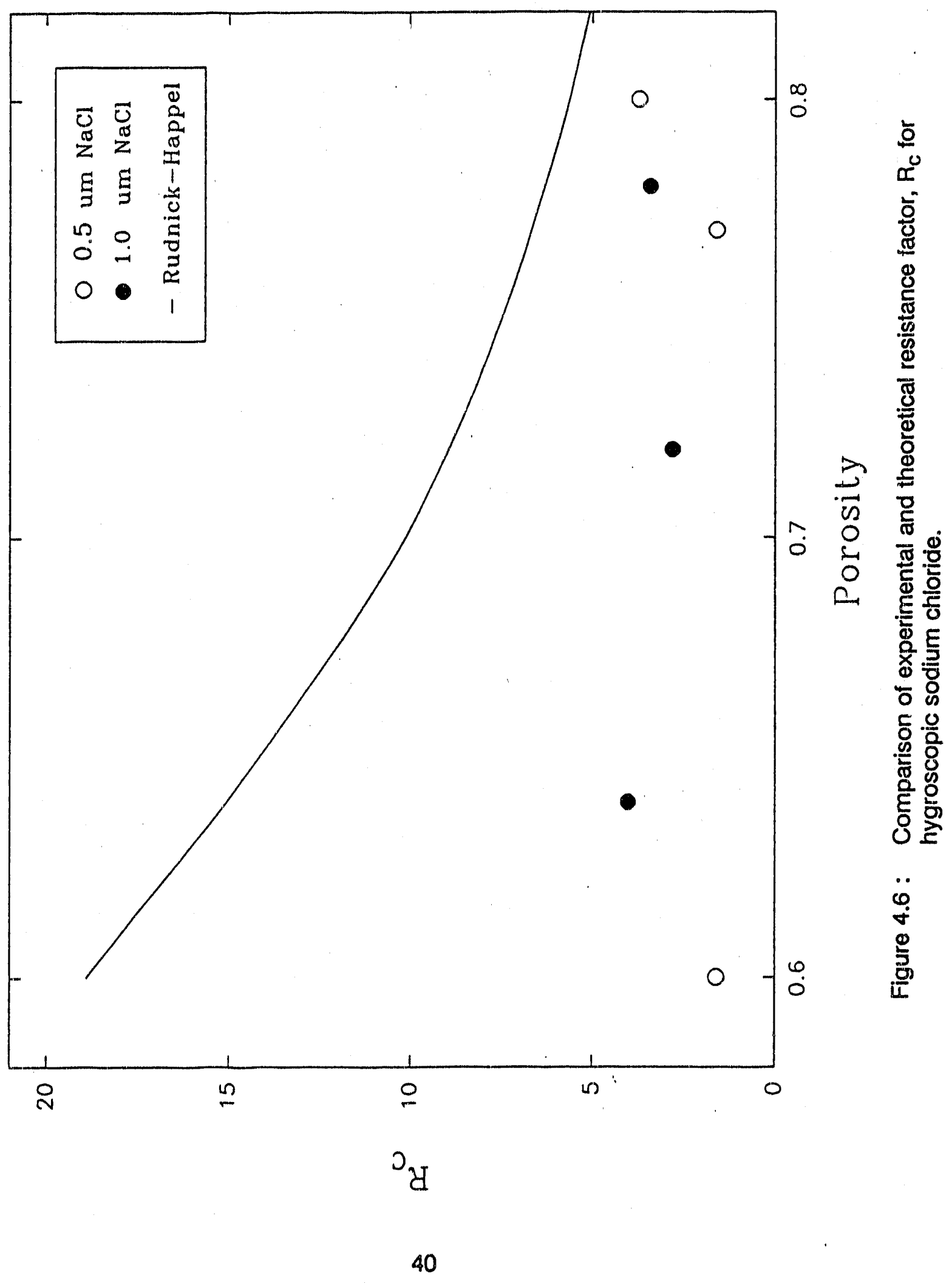




\subsubsection{Results of Hygroscopic Tests Above Deliquescent Point}

Above the deliquescent humidity the pressure drop increases linearly with mass loading in the very early stages of mass loading, approximately up to $0.0006 \mathrm{~g}^{\mathrm{cm}}{ }^{-2}$. The $K_{2}$ values computed from the linear portion of the curves are equal to 370875 and 381625 $\left(s^{-1}\right)$ at the humidities of $80 \%$ and $90 \%$ respectively for the larger $\mathrm{NaCl}$ droplets whereas for the smaller $\mathrm{NaCl}$ droplets they are equal to 515125 and $516950\left(s^{-1}\right)$ respectively at the two humidities. When compared to the $\mathrm{K}_{2}$ values for solid $\mathrm{NaCl}$ particles (below the deliquescent point), these values are of the same order of magnitude (Table 4.3). Furthermore, the calculated $\mathrm{K}_{2}$ values are smaller for the larger $\mathrm{NaCl}$ droplets as compared to the values for the smaller $\mathrm{NaCl}$ droplets indicating a size effect similar to the solid particles. However, with continued loading the pressure drop increase becomes non-linear, and this is shown for messurements at $80 \%$ and $90 \%$ humidities in Figures 4.7 to 4.10 for the $0.5 \mu \mathrm{m}$ and $1.0 \mu \mathrm{m}$ MMD dry size $\mathrm{NaCl}$ particles respectively. Due to the overall non-linearity of pressure drop with mass loadings the specific cake resistance, a constant $K_{2}$ is not defined. Moreover, at humiditles above the deliquescent point, the aerosol is in the form of droplets, which on collection, percolate into the filter due to capillary action rather than forming a cake. Inside the filter these droplets start filling up the interstitial spaces between the filter fibers. With continued filling of the interstitial spaces, the pressure drop increases non-linearly and finally reaches a maximum when the interstitial space is completely filled. The results in Figures 4.7 to 4.10 indicate that this non-linearity or sudden increase in pressure drop is initiated at lower mass loadings for humidities closer to the deliquescent point. The size of the droplet at humidities above the deliquescent point is determined by liquid-vapor equilibrium considerations. If the initial particle size (dry) is same, the concentration of the droplet solution is lower 
at higher humidities (droplet size larger at higher humidities). Thus, at a lower humidity, the surface tension of the droplet is higher and consequently, resistance to percolation into the filter interstitial spaces is also higher due to reduced capillary action. As a result of reduced capillary action, the interstitial spaces near the surface are filled and the nonlinearity or the sudden increase in pressure drop is initiated at lower mass loadings for humidities closer to the deliquescent point for the same initial (dry) size of $\mathrm{NaCl}$ particles (Figures 4.7 and 4.8, 4.9 and 4.10). For different initial (dry) size $\mathrm{NaCl}$ particles (Figures 4.7 and 4.9, 4.8 and 4.10) the solution concentrations are same at the same humidity (dictated by equilibrium conditions) and therefore, according to the above reasoning the Initiation of non-linearity should also be at the same mass loading. However, due to differences in the size of the droplets approaching the filter $(3.12 \mu \mathrm{m}$ in Figure 4.9 compared to $1.26 \mu \mathrm{m}$ in Figure 4.7) and the flow patterns inside the filter holder, the larger droplets tend to deposit in the central region of the filter whereas the smaller droplets distribute themselves over a larger portion of the filter. Such a deposition pattern of the large droplets delays the complete filling up of the interstitial space, consequently, the sudden increase in the pressure drop is delayed. 


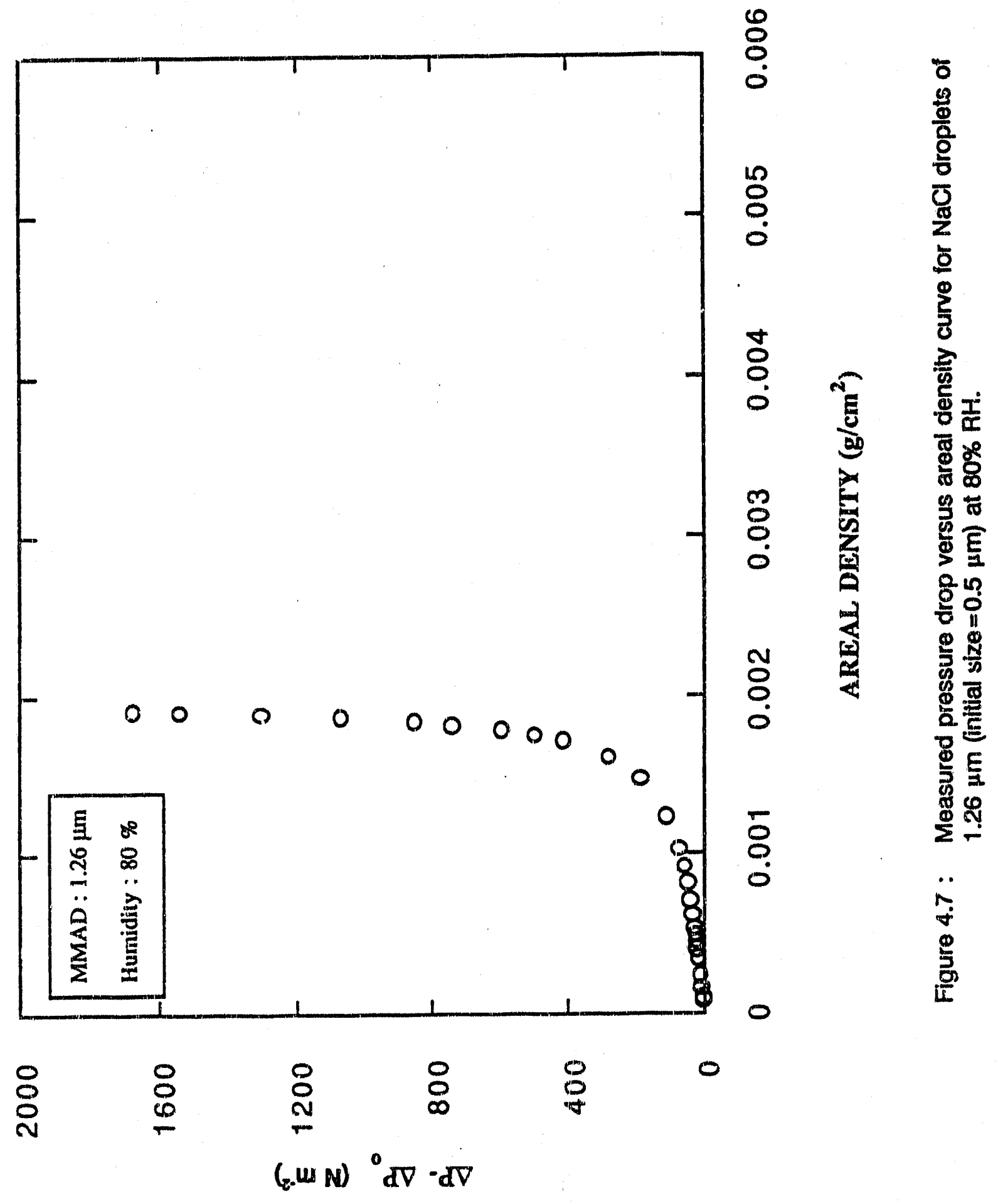




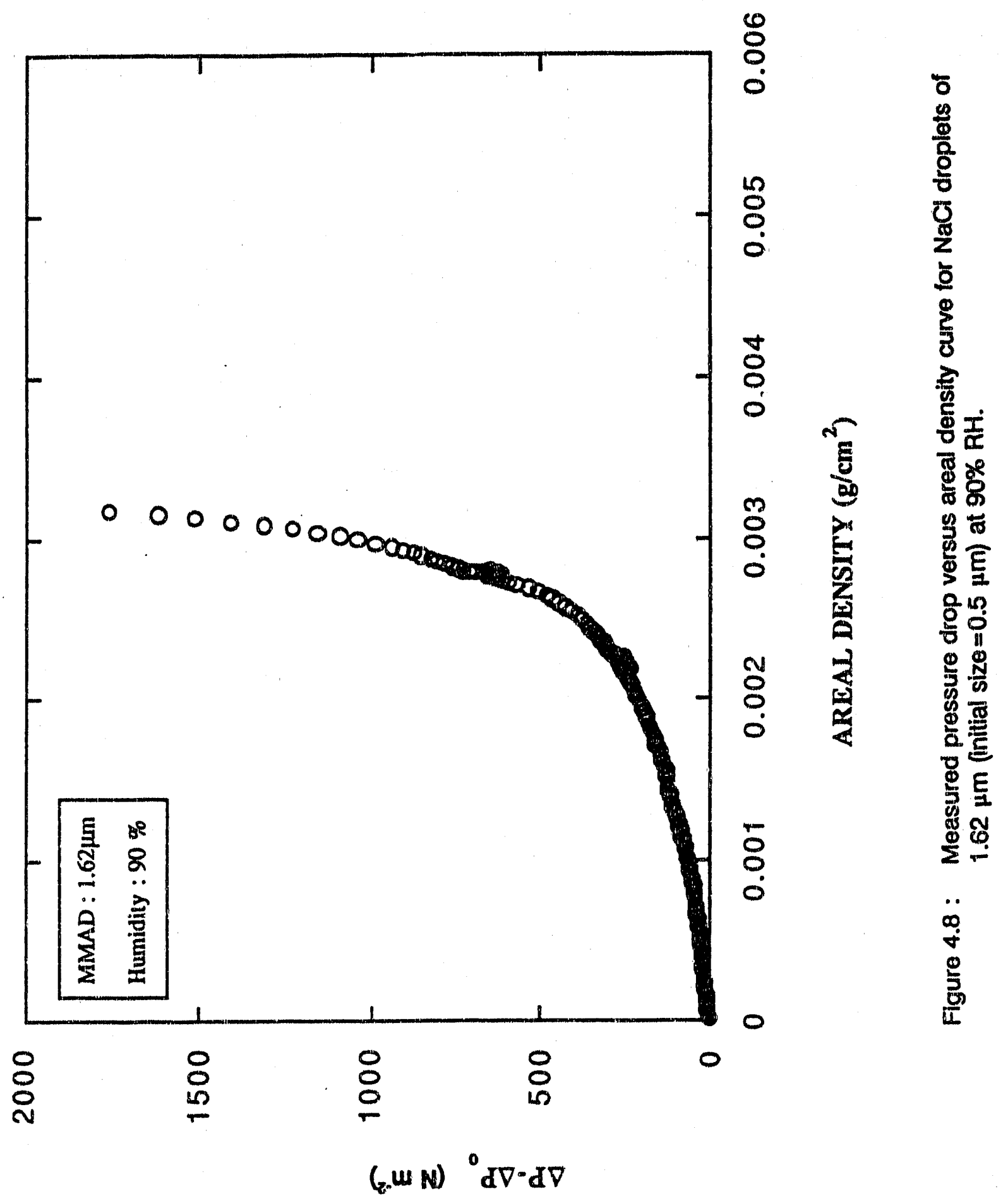




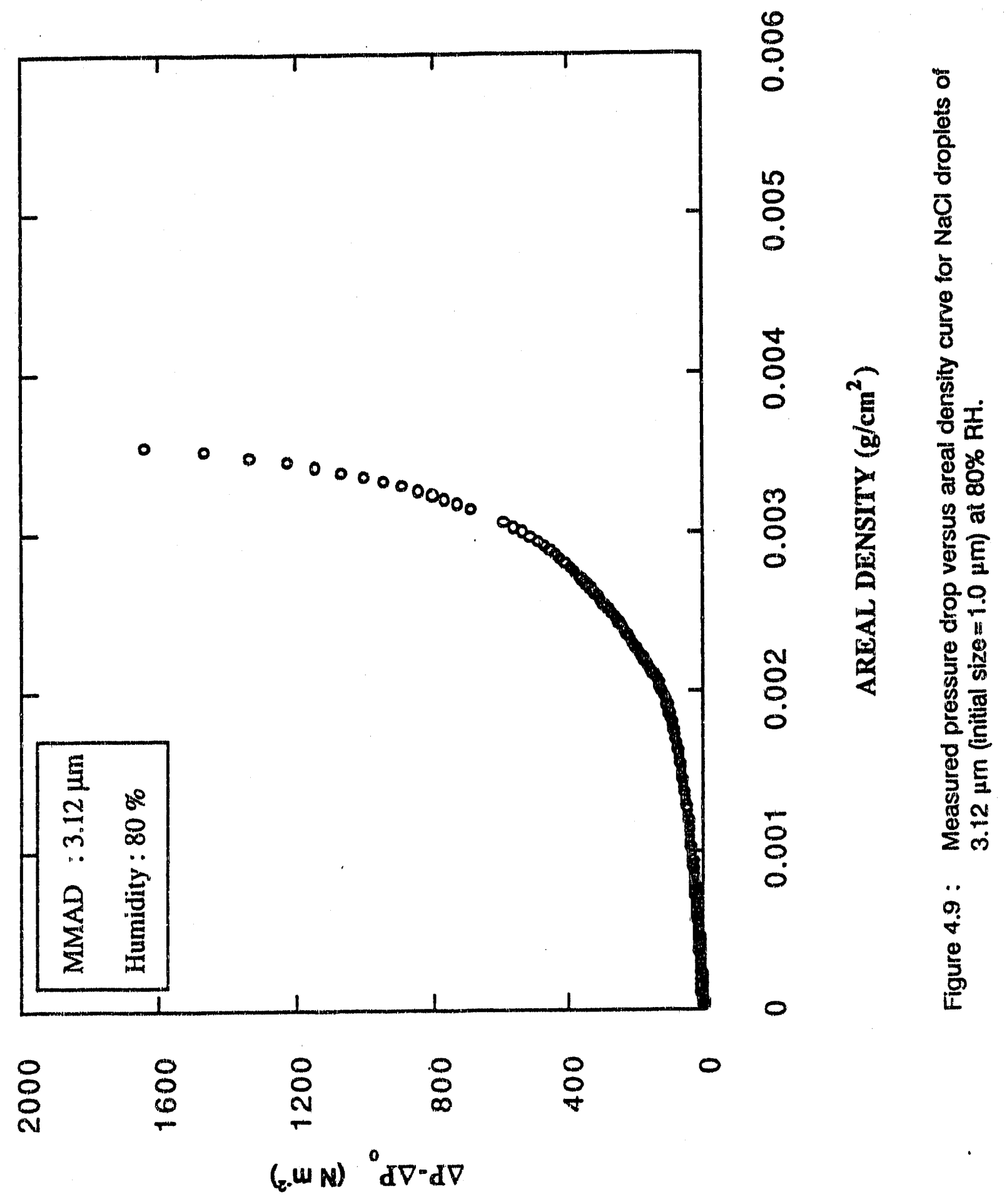




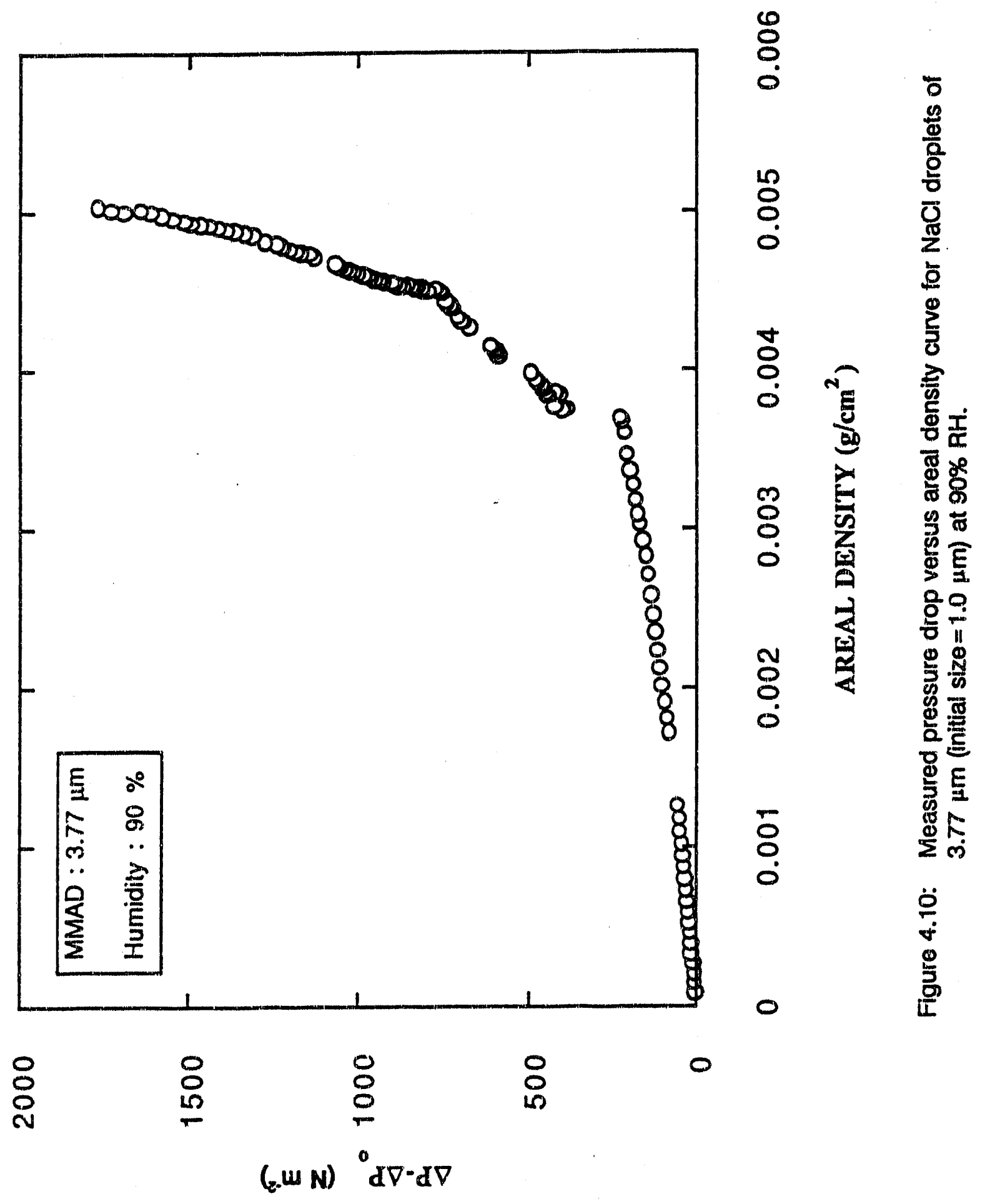




\section{CHAPTER 5}

\section{CONCLUSIONS AND RECOMMENDATIONS}

\subsection{Conclusions}

(1) A decrease in the specific cake resistance, $K_{2}$, with increasing humidity (from $1 \%$ to $100 \% \mathrm{RH})$ for the two nominal sizes $(0.5 \mu \mathrm{m}$ and $1.0 \mu \mathrm{m})$ of the non-hygroscopic aluminum oxide particles was observed. However, the decrease in $K_{2}$ for the $0.5 \mu \mathrm{m}$ particles was evident only at humidities higher than $90 \% \mathrm{RH}$ whereas for the $1.0 \mu \mathrm{m}$ particles the decrease was observed in the entire range of the humlditles studied. A similar decrease in $\mathrm{K}_{2}$ was observed for the two sizes of the hygroscopic $\mathrm{NaCl}$ particles at humidities below the deliquescent point $(75 \%$ RH). Unlike, aluminum oxide, the decrease was continuous for the two $\mathrm{NaCl}$ particle sizes. The observed decrease in $\mathrm{K}_{2}$ suggests that humidity enhances the mass loading capacity of the tested HEPA filter material (glass fiber) for non-hygroscopic and hygroscupic materials at relative humidities below the deliquescent point. These effects are postulated to be due to alterations in the structure of the cake formed under humid conditions. The decrease in pressure drop with mass loading (or decrease of $K_{2}$ ) at elevated humidities is also dependent on the nature of particles (hygroscopicity) and deposition patterns which are size dependent. However, more studies need to be conducted with different non-hygroscopic and hygroscopic materials to quantitatively establish these trends and relate to physical and chemical properties of the aerosol. 
(2) Above the deliquescent point the mass loading capacity of the filter is drastically reduced because of the change in the phase of the hygroscopic aerosol particles. At these humidities, the surface tension of the aerosol droplets and their penetration into the filter material are inversely related. Hence, a continuous liquid film over the filter surface is formed at a lower mass loading for humidities closer to the deliquescent point, further reducing the mass loading capacity. Hence, extreme caution must be exercised in predicting the maximum loading of hygroscopic aerosols on filters at humidities above their deliquescent point.

(3) The resistance factor, $R$, for the particulate cake consisting of non-hygroscopic aluminum oxide particles of either size $(0.5 \mu \mathrm{m}$ and $1.0 \mu \mathrm{m} \mathrm{MMD)}$ and at all the humidities studied can be estimated by Rudnick-Happel expression with reasonable accuracy. The limitations in the porosity data were more apparent in the case of hygroscopic $\mathrm{NaCl}$ where the experimental $\mathrm{R}$ and the $\mathrm{R}$ calculated using Rudnick-Happel were far apart. To avoid the problems posed by the theretical approach for predicting $K_{2}$ it might be worth while to develop semi-empirical equations relating $R$ with particle size for different types of aerosols frequently subjected to filtration in industry. This eliminates the problem associated with determining an accurate cake porosity.

\subsection{Recommendations for Future Work}

(1) The results of this study show that the specific cake resistance decreases with increasing humidity for the $1.0 \mu \mathrm{m} \mathrm{MMD} \mathrm{non-hygroscopic} \mathrm{aluminum} \mathrm{oxide} \mathrm{and} \mathrm{the} \mathrm{two}$ sizes (0.5 and $1.0 \mu \mathrm{m} \mathrm{MMD)} \mathrm{of} \mathrm{hygroscopic} \mathrm{NaCl}$ below the deliquescent point. At the same time the change in the specific cake resistance with increasing humidity for the 
non-hygroscopic aluminum oxide was evident only after $90 \% \mathrm{RH}$. Therefore, more studies need to be conducted with different non-hygroscopic and hygroscopic materials for a complete qualitative and quantitative explanation relating to physical and chemical properties of the aerosol.

(2) The errors associated with the cake porosity estimation can only be eliminated by developing a technique capable of measuring cake porosity in-situ. Such technique will help in the development of more reliable theories pertaining to the cake resistance factor such that cake pressure drop can be predicted using the known properties of the filtered aerosol rather than depending on the simulated experiments. 


\section{REFERENCES}

Ariman, T. and Helfritch, D. J. (1977), "How Relative Humidity Cuts Pressure Drop in Fabric Filters", Filtration and Separation, $14:$ 127-130.

Biswas, P., Jones, C. L., and Flagan, R. (1987), "Distortion of Size Distributions by Condensation and Evaporation in Aerosol Instruments", Aerosol Sci. and Tech., 7:2312.46.

Biswas, P., LI, X., and Pratsinis, S. E. (1989), "Optical Waveguide Preform Fabrication : Silica Formation and Growth in a High-Temperature Aerosol Reactor", J. Appl. Phys., 65:2445-2450.

Buckle, E. R. (1991), "Nucleation and Growth of Caesium lodide Aerosols", L Aerosol Sci., 22 : 135-147.

Carr, R, L. (1969), "Properties of Solids", Chemical Engineering, October $1969: 8$.

Copus, E. R., Bloes, R. E., Brockmann, J. E., Gomez, R. D. and Lucero, D. A (1990), "Experimental Results of Core-Concrete Interactions Using Molten Steel with Zirconium", NUREG/CR 4794, Sandia National Laboratory Report No. SAND 86-2638.

Cuddihy, R. G., Finch, G. L., Newton, G. J., Hahn, F.F., Mewhinney, J. A., Rothberg, S. J. and Powers, D. A. (1989), "Characteristics of Radioactive Particles Released from the Chernobyl Nuclear Reactor, Environmental Sci. and Tech., 23:89-95. 
Durham, J. F. and Harrington, R. E. (1971), "Influence of Relative Humidity on Filtration Resistance and Efficiency of Fabric Dust Filters", Filtration and Separation, July/August : 389-398.

Hasenclever, D. (1971), "Filters for Air and Gas Cleaning in Nuclear Installations", Staub, 31-2: 1-8.

Leith, D. and Allen, R. W. K. "Dust Filtration by Fabric Filters" in Progress in Filtration and Separation, Vol 4, Wakeman R. J. (ed.), Elsevier, 1986.

Novick, V. J. and Higgins, P. J. (1989), "Phase I: Characterization of the HEPA Filter Media Used in the Airborne Activity Confinement System at the Savannah River Site", Westinghouse Savannah River Report No. WSRC-RP-89-793.

Novick, V. J., Abrahamson, C. A., and Richardson, W. B.(1990), "Relationship Between the Pressure Drop Across the Savannah River Site's HEPA Filter Material and Aerosol Mass Loading", Westinghouse Savannah River Report No. WSRC-RP-90$\underline{779}$.

Rudnick, S. N. (1978),"Fundamental Factors Governing Specific Cake Resistance of Filter Dust Cakes", S. D. Thesis, Harvard School of Public Health, Boston, Massachusetts. 
Smith, P.R., Schlutheis, T. M., Walls, J. R. and Gregory, W.S. (1990), "Investigation of

Salt Loaded HEFA Filters", 21 $1^{\text {st }}$ DOE/NRC Nuclear Air Cleaning Conference. 1990.

Tang, I. N., Munkelwitz, H. R. and Davis, J. G. (1977), "Aerosol Growth Studies - II : Preparation and Growth Measurements of Monodisperse Salt Aerosols", J. Aerosol Sci., 8 : 149-159.

Tillery, M. 1.(1987), "High Efficiency Air Filtration", in Filtration Principles and Practices, Matteson, M. J. and Orr, C. (Eds.), 2nd ed., Marcel Decker Inc., New York.

Williams, K. L. and Vinson, R. P. (1986), "Evaluation of the TEOM Dust Monitor", Bureau of Mines Information Circular No. 9119.

Whitby, R., Johnson, R. and Gibbs, R. (1985), "Second Generation TEOivi Filters Diesel Particulate Mass Comparisons Between TEOM and Conventional Filtration Techniques", SAE Technical Paper Series No. 850403.

Zimon, A. D.(1969) Adhesion of dusts and Particles, Plenum Press. 


\section{APPENDIX - 1 \\ Derivation of the Expression for Specific Cake Resistance $\left(K_{2}\right)$}

The drag force $\left(f_{d}\right)$ on a perfectly rigid spherical particle with a Reynolds number less than 1 is given by Stokes law

$$
f_{d}=3 \pi d \mu V
$$

where $\mu$ is the gas viscosity, $d$ is the particle size and $V$ is the filtration velocity

To account for the slip between a small particle and the gas medium, Cunningham Slip Correction Factor, $\mathrm{C}$, is often used

$$
f_{d}=\frac{3 \pi d \mu V}{C}
$$

For " $n$ " identical particles, the total drag is

$$
F_{T}=n f_{d}=n\left(\frac{3 \pi \mu V d}{C}\right)
$$

Pressure drop developed due to this drag force

$$
\Delta P_{\text {cake }}=\frac{F_{T}}{A}=\frac{1}{A} n\left(\frac{3 \pi \mu V d}{C}\right)
$$


where $A$ is the filtration area.

The specific cake resistance, $K_{2}$, is defined as

$$
K_{2}=\frac{\Delta P_{\text {cake }}}{V\left(\frac{M}{A}\right)}
$$

where $M$ is the mass collected on the filter. Using $M=n \pi\left(d^{3} / 6\right) \rho_{g}$ and substituting in equation (1-4) the following expression for $K_{2}$ can be arrived at

$$
K_{2}=\frac{18 \mu}{C \rho_{g} d^{2}}
$$

This expression is valid for a monodisperse particle distribution. If the particles present on the filter are size distributed with " "i" size categories containing " $n$ " particles each, then the total drag becomes

$$
F_{T}=\Sigma f_{a l}=\Sigma_{i 1}\left(\frac{3 \pi \mu \vee d_{1}}{C}\right)
$$

Pressure drop developed due to this drag force

$$
\Delta P=\frac{F_{T}}{A}=\frac{1}{A} \sum n_{1}\left(\frac{3 \pi \mu V d_{l}}{C}\right)
$$

Using particle volume $(v)$ instead of size $\left(d=(v 6 / \pi)^{1 / 3}\right)$ and integrating the above equation for all particle volumes, the following expression for pressure drop can be derived 


$$
\Delta P=\frac{1}{A} \int_{0}^{\infty}\left(\frac{3 \pi \mu V}{C}\right)\left(\frac{V 6}{\pi}\right)^{1 / 3} n(V) d V
$$

Further simplifying the equation

$$
\Delta P_{\text {cakso }}=\frac{3 \pi \mu V}{(\pi / 6)^{1 / 3} A} \int_{0}^{\infty} \frac{V^{1 / 3}}{C} n(V) d v
$$

Assuming $C$ to be evaluated at the geometric mean size, equation $(1-10)$ reduces to

$$
\Delta P_{\text {cake }}=\frac{3 \pi \mu V}{(\pi / 6)^{1 / 3} A} \frac{M_{1 / 3}}{C}
$$

where $M_{1 / 3}$ is the $1 / 3^{\text {rd }}$ volume moment of the aerosol size distribution. For lognormally distributed aerosols the $k^{\text {th }}$ moment, $M_{k}$, is expressed in termis of the zeroth moment, $M_{0}$ (Biswas et al., 1989)

$$
M_{k}=M_{0} v_{g}^{k} \exp \left(4.5 k^{2} \ln ^{2} \sigma\right)
$$

Using $k=1 / 3$ in equation $(1-12)$ and substituting in equation $(1-11)$ we have

$$
\Delta P_{\text {cake }}=\frac{3 \pi \mu \vee M_{0}}{A(\pi / 6)^{1 / 3} C v_{g}^{2 / 3}} \exp \left(0.5 \ln ^{2} \sigma_{g}\right)
$$

where $v_{g}$ is the geometric volume mean and $\sigma_{g}$ is the geornetric standard deviation. Physically, $M_{1}$ is the total volume of the particles collected on the filter and hence $\rho_{p} x$ $M_{1}$ represents the total mass collected $(M)$ on the filter. Multiplying and dividing the above equation by $\rho_{p} \times M_{1}$ gives 


$$
\Delta P_{\text {cake }}=\frac{3 \pi \mu V M v_{g}^{1 / 3}}{A \rho_{p}(\pi / 6)^{1 / 3} C} \frac{\exp \left(0.5 \ln ^{2} \sigma_{g}\right)}{\exp \left(4.5 \ln ^{2} \sigma_{g}\right)}
$$

where $M_{1}$ is the first aerosol moment and is defined by equation (1-12). After further simplification equation $(1-14)$ reduces to

$$
\Delta P_{\text {cake }}=\frac{3 \pi \mu V M}{A \rho_{p}(\pi / 6)^{1 / 3} C v_{g}^{2 / 3}} \exp \left(-3 \mid n^{2} \sigma_{g}\right)
$$

Using $d_{g}=\left(v_{g} 6 / \pi\right)^{1 / 3}$ and the definition of specific cake resistance (equation (1-5)), for a polydisperse aerosol with the slip correction factor evaluated at the geometric mean diameter $\left(d_{g}\right)$, the specific cake resistance, $K_{2 c}$, is given by

$$
K_{2 C}=\frac{18 \mu}{\rho_{p} d_{g}^{2} C} \exp \left(-4 \ln ^{2} \sigma_{q}\right)
$$

where $d_{g}$ is the geometric mean diameter of the particle size distribution which can be calculated from mass median diameter obtained from impactor data (Hinds, 1982)

$$
d_{g}=d_{m m} \exp \left(-3.5 \mathrm{ln}^{2} \sigma_{q}\right)
$$

Substituting in equation (1-16) we get

$$
K_{2 c}=\frac{18 \mu}{P_{p} \sigma_{m m}^{2} C} \exp \left(3.0 \mathrm{In}^{2} \sigma_{\partial}\right)
$$

In the limit $\sigma_{g} \rightarrow 1$ (monodisperse particles), $K_{2 c}$ in equation (1-15) approaches $K_{2 s t o k e s}$ in equation (I-6). 


\section{APPEINDIX-II}

Propertles of Test Aerosoll Materials

Table II-1 : Properties of Hygroscople Sodium Chloride

\begin{tabular}{|c|c|}
\hline Deliquescent Point' & $75 \% \mathrm{RH}$ \\
\hline Crystallization Point $^{\prime}$ & $44 \% \mathrm{RH}$ \\
\hline Density & \\
\hline Source & $2.164\left(\mathrm{~g} \mathrm{~cm}^{-3}\right)$ \\
\hline
\end{tabular}

Table Il-2 : Properties of Non-hy/groscopic Aluminum Oxide

\begin{tabular}{|c|c|}
\hline Density & $3.9\left(\mathrm{~g} \mathrm{~cm}^{2}\right)$ \\
\hline Morphology & Irregular \\
\hline Source & Fujimi Corporation \\
\hline
\end{tabular}

1 Tang et al., 1977

${ }^{2}$ CRC Handbook of Chemistry and Physics (1976),

${ }^{3}$ Fujimi Corporation, Elmhurst, Illinois 


\section{APPENDIX - III \\ Humidifier Calibrations}

To callbrate the humidifier (Figure III-1), a water bath was heated to various temperatures and the resulting RH was measured in the sampling chamber. The flow through the bath was set at $0.75 \mathrm{lpm}$ and the flow through the experimental apparatus was set equal to the total actual flow rate of $6.21 \mathrm{pm}$. With the bath temperature constant, the RH was recorded as a function of time. The data used for the humidifier calibrations is presented in Table III-1.

Table III-1 : Humidifier Calibration Data (Raw)

\begin{tabular}{|c|c|c|}
\hline $\begin{array}{c}\text { Bath Temperature } \\
(\mathrm{F})\end{array}$ & Average RH (\%) & $\begin{array}{c}\text { Average Gas } \\
\text { Tomporature } \\
\text { (F) }\end{array}$ \\
\hline 79.0 & Experiment \# 1 & \\
\hline 102.0 & 25.5 & 74.7 \\
\hline 110.5 & 43.2 & 72.5 \\
\hline 120.5 & 49.6 & 72.7 \\
\hline 130.0 & 61.2 & 72.8 \\
\hline 146.0 & 73.9 & 73.3 \\
\hline & 99.3 & 73.4 \\
\hline 80.0 & Experiment \# 2 & \\
\hline 104.0 & 26.1 & 68.8 \\
\hline 109.5 & 42.6 & 69.6 \\
\hline 121.0 & 45.3 & 70.2 \\
\hline 131.0 & 58.8 & 70.8 \\
\hline 138.0 & 72.6 & 70.8 \\
\hline 146.0 & 95.6 & 68.7 \\
\hline 146.0 & 98.8 & 69.3 \\
\hline & 99.3 & 73.4 \\
\hline
\end{tabular}


Average $\mathrm{RH}$ values from experiment \# 2 were extrapolated to the values corresponding to the gas temperature of experiment \# 1. These values are presented in Table III-2.

Table III-1 : Humidifler Calibration Data (Corrected)

\begin{tabular}{|c|c|c|}
\hline $\begin{array}{c}\text { Bath } \\
\text { Temperature } \\
(\mathrm{F})\end{array}$ & $\begin{array}{c}\text { Extrapolated Avg. } \\
\mathrm{RH}(\%) \text { of \# 2 }\end{array}$ & $\begin{array}{c}\text { Gas } \\
\text { Temperature } \\
(\mathrm{F})\end{array}$ \\
\hline 80.0 & 22.0 & 74.7 \\
\hline 104.0 & 40.0 & 73.0 \\
\hline 109.5 & 43.0 & 72.0 \\
\hline 121.0 & 56.0 & 73.0 \\
\hline 131.0 & 69.0 & 73.5 \\
\hline 138.0 & 84.0 & 73.0 \\
\hline 146.0 & 89.0 & 73.5 \\
\hline
\end{tabular}

The extrapolated $\mathrm{RH}$ values from experiment \# 2 and the $\mathrm{RH}$ values of experiment \# 1 were then plotted as a function of water bath temperature (Figure III-1). An exponential curve fitted the data with a regression coefficient, $R=0.99$. Reproducib lity was found to be $\pm 3 \%$ full scale $(100 \% \mathrm{RH})$ with respect to the fitted curve. The maximum deviation of the humidity measurements about the average for a given temperature was $\pm 3.1 \%$. 


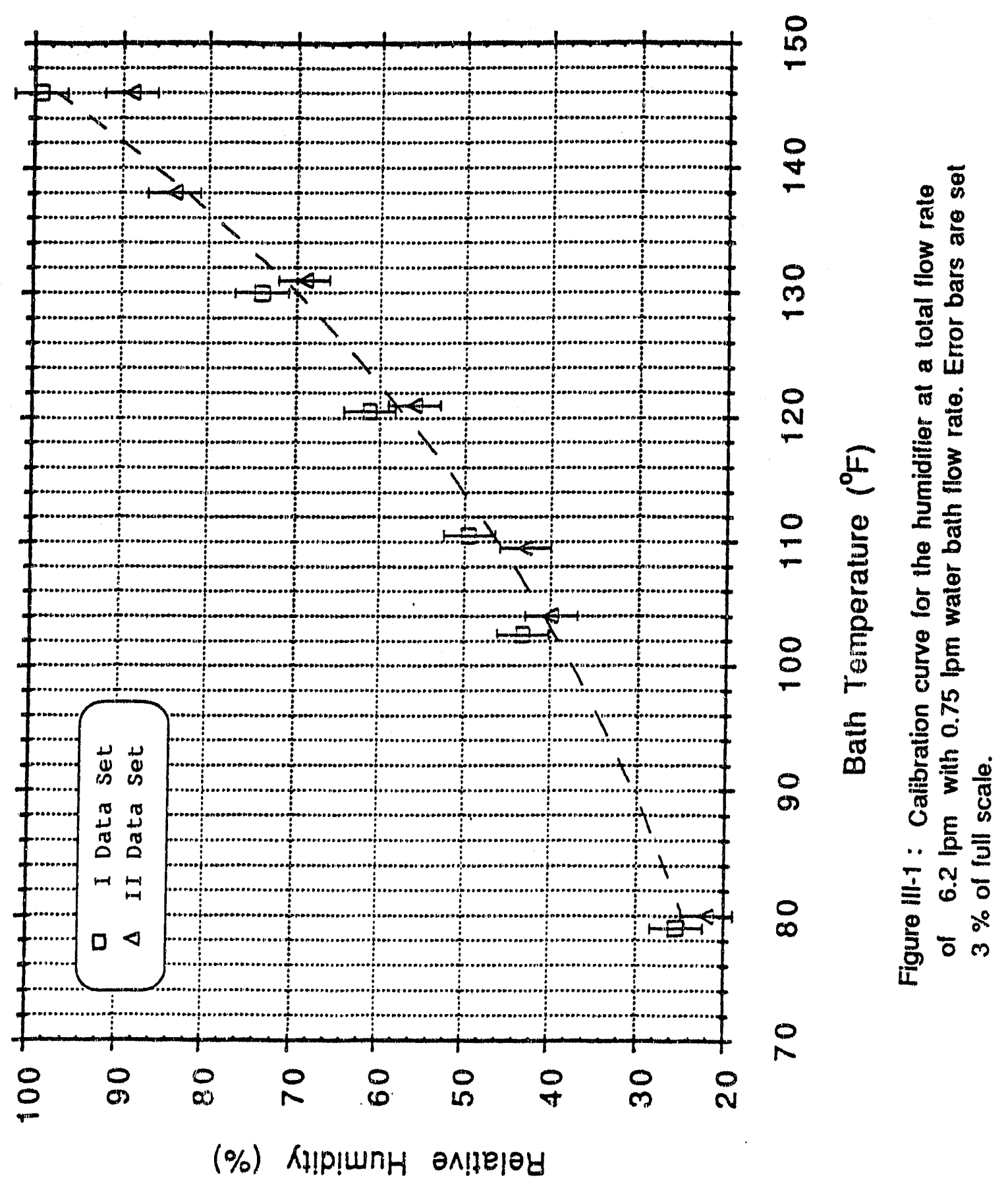




\section{APPENDIX - IV}

\section{TEOM Characteristics}

\section{IV.1 Performance of TEOM}

The TEOM has been tested for its accuracy and repeatability by various researchers. Whitby et al. (1985) studied the diesel particulate loading between a TEOM and $47 \mathrm{~mm}$ filtration techniques. They reported that the TEOM typically collected $23 \%$ less mass than the $47 \mathrm{~mm}$ filter at a given temperature. Differences in mass determinations were attributed to differences in volatile species retained by the filters. The difference in retention of volatile species by the TEOM filter was attributed to the higher $\triangle P$ across the TEOM filter. Otherwise, they found the TEOM instrument capable of measuring the mass collected on the TEOM filter with accuracy and precision essentially on par with gravimetric techniques. Since volatile species were not involved in the present study and the filters and pressure dropo were identical, the use of TEOM was justified.

In an another study, Williams and Vinson (1986) compared the TEOM dust monitor with a personal dust sampler. They reported excellent agreement between the TEOM and the personal sampler. Further, they observed that the TEOM performance is affected only if it is used such that the stem oscillations parallel to gravity. In these orientations, the stern oscillations are affected by gravity causing variations in the data. In the present study the TEOM was used upside-down such that stem oscillations were transverse to the gravity as the case would be in the normal position. Therefore, use of the TEOM in an inverted position will not affect the instrument performance. However, to further ascertain the characteristics of the TEOM for the given system and conditions, tests were 
conducted in which samples were collected to compare the performance of the TEOM, in an inverted position, with two $47 \mathrm{~mm}$ filters. The face velocities in the two $47 \mathrm{~mm}$ filter holders were calculated to be $2.6 \%$ apart. Therefore, their agreement in measuring the specific cake resistance was expected to be at least $2.6 \%$ apart. The experimental deviation in the $47 \mathrm{~mm}$ data was found to be $3.14 \%$. After correcting for the variation in the flow rates, the $47 \mathrm{~mm}$ specific cake resistance data agreed to within $1.5 \%$. The TEOM measured specific cake resistance was found to deviate $0.7 \%$ from the average of the $47 \mathrm{~mm}$ data. This adequately demonstrates the viability of a TEOM as the primary filter testing device if identical filter media and media velocities are used, and as long as care is taken to sample representatively and to maintain uniform mass loading across the filter surface. The parameter used in the evaluation is specific cake resistance. The results of this test are tabulated in Table IV-1.

TABLE IV-1 : TEOM Performance Data

\begin{tabular}{|c|c|c|c|}
\cline { 2 - 4 } \multicolumn{1}{c|}{} & $\begin{array}{c}47 \mathrm{~mm} \\
\text { Filter \# 1 }\end{array}$ & $\begin{array}{c}\text { TEOM } \\
\text { Filter }\end{array}$ & $\begin{array}{c}47 \mathrm{~mm} \\
\text { Fitter \#2 }\end{array}$ \\
\hline Filtration Area $\left(\mathrm{cm}^{2}\right)$ & 13.2208 & 1.2517 & 12.7329 \\
\hline Mass Deposited $(\Delta M),(g)$ & 0.1488 & 0.0151 & 0.1605 \\
\hline$\Delta P_{\text {cake }}(\mathrm{Pa})$ & 1525.0 & 1675.0 & 1762.5 \\
\hline Filtration Volocity, $\left(\mathrm{cm} \mathrm{s}^{-1}\right)$ & 3.0905 & 3.115 & 3.1318 \\
\hline$\left.K_{2}{ }^{*}=\Delta P / N \Delta M / A\right),\left(\mathrm{s}^{-1}\right)$ & 43840.4 & 43975.4 & 44642.9 \\
\hline
\end{tabular}

\section{DATA ANALYSIS}

Assumption :47 $\mathrm{mm}$ data is representative

$\begin{array}{lll}\text { Average }\left(K_{2}\right)_{47 \mathrm{~mm}} & =44241.7 \mathrm{~s}^{-1} \\ \text { Deviation in } 47 \mathrm{~mm} \text { filters } & =1.5 \% \\ \text { TEOM Deviation } & =0.7 \%\end{array}$




\section{IV.2 TEOM Pressure Transducer Calibrations}

The TEOM pressure transducer was calibrated against a water manometer. A series of vacuum levels were applied simultaneously to the combination of water manometer and the pressure transducer. The generated transducer voltage was recorded as a function of applied pressure. At least five voltage readings were taken at a given pressure. The applied pressure was then plotted as a function of voltage. A fifth order polynomial was fitted to the data and the coefficients were incorporated in the TEOM software. This exercise was done a number of times to maintain the accuracy of the pressure transducer throughout the duration of experimentation. Table IV-2 presents a sample set of calibration data and the fitted equation.

Table IV-2 : TEOM Pressure Transclucer Calibrations Data

\begin{tabular}{|c|c|c|c|c|c|c|}
\hline \multirow{2}{*}{$\begin{array}{c}\text { Manometer } \\
\text { Reading } \\
\text { (wg) }\end{array}$} & \multicolumn{6}{|c|}{ Pressure Transducer Voltage (volts) } \\
\hline & 1 & 2 & 3 & 4 & 5 & Average \\
\hline 0.0 & 0.003 & 0.003 & 0.003 & 0.003 & 0.003 & 0.0030 \\
\hline 1.0 & 0.122 & 0.122 & 0.123 & 0.123 & 0.123 & 0.1226 \\
\hline 2.0 & 0.288 & 0.288 & 0.294 & 0.295 & 0.291 & 0.2912 \\
\hline 3.0 & 0.477 & 0.475 & 0.475 & 0.474 & 0.479 & 0.4760 \\
\hline 4.0 & 0.684 & 0.687 & 0.685 & 0.689 & 0.687 & 0.6864 \\
\hline 5.0 & 0.890 & 0.890 & 0.887 & 0.887 & 0.883 & 0.8894 \\
\hline 6.0 & 1.133 & 1.142 & 1.145 & 1.139 & 1.146 & 1.1410 \\
\hline 7.0 & 1.343 & 1.344 & 1.346 & 1.353 & 1.347 & 1.3466 \\
\hline 8.0 & 1.562 & 9.581 & 1.571 & 1.561 & 1.571 & 1.5652 \\
\hline 8.0 & 1.755 & 1.764 & 1.761 & 1.761 & 1.759 & 1.7600 \\
\hline 10.0 & 1.973 & 1.963 & 1.872 & 1.876 & 1.967 & 1.902 \\
\hline
\end{tabular}


Equation of the curve fit is :

$$
\begin{aligned}
& \Delta P=2.1254 * 10^{-3}+8.2965 * v-5.6428 * v^{2}+3.7364 * v^{3}- \\
& 1.0936 * v^{4}+0.11675 * v^{5} ; R=1.0
\end{aligned}
$$

where $v$ is the pressure transducer voltage

64 


\section{APPENDIX - V}

\section{Representative Sampling Characteristics of the Sampling System}

Tests carried out to evaluate the viability of the TEOM as a primary filter testing device were also designed to test the sampling characteristics of the system. Two $47 \mathrm{~mm}$ filter holders were used as the referernes and were placed on the either side of the TEOM. All three sampled aerosol from a sampling system. In some of the sampling system configurations tested for representative sampling characteristics, particle sampling was assisted by gravity. In these tests the three filters were found to be as much as $13 \%$ apart. The parameter used for comparisons was specific cake resistance. The major cause of the disagreement was found to be the non-uniform distribution of particles over the filter surface. Alded by gravity particle agglomerates gained inertia and were not able to follow the diverging streamlines inside the filters holders and were preferentially deposited on the center of the filters. To avoid such deposition pattern, the sampling chamber and the filters were mounted in an inverted configuration (Figure 4) such that the sampling was done against the gravity. By doing so, the particle agglomerates prevented from gaining high inertia and therefore, were more uniformly distributed on the filters as demonstrated by a good agreement (within $0.7 \%$ ) in the specific cake resistance for the three filters (Table IV-1). Thus, representative sampling was made possible irrespective of the differences in the flow rates through the TEOM and the $47 \mathrm{~mm}$ filter holders. Typically, the flow through the TEOM (0.2 lpm) was one order of magnitude lower than the flow through the $47 \mathrm{~mm}$ filters $(2.3 \mathrm{lpm})$. The flow through the impactor $(5.0 \mathrm{lpm})$ used for particle size distribution measurements was approximately twice that 
through the $47 \mathrm{~mm}$ filter. Since the three sampling ports had demonstrated representative sampling characteristics over a the flow range of an order of magnitude, it was reasonable to expect that the impactor sample would also be representative. 


\section{APPENDIX - VI \\ Impactor Mach Number Calculations}

The six stage cascade impactor (Intox Products, Model 5B) used for particle size distribution measurements in the study was designed for a flow rate of $5 \mathrm{lpm}$. Studies by Biswas et al. (1987) observed that most particle size distribution measuring devices tend to be biased while sampling humid aerosols. In an impactor, repeated expansion of the Inlet gas stream through the jets causes a decrease in gas temperature and pressure progressively with each stage causing water vapor to condense under high humidity conditions. Specifically, the study reported that if the Mach Number in all the stages can be maintained below 0.005 , the blas in particle size measurements due to condensed water droplets would be minimal even at relative humidities exceeding $90 \%$. The Mach Number is highest for the last or the stage having maximum number of jets. For the given impactor, the sixth stage had 40 jets each with a diameter of $0.152 \mathrm{~cm}$. Below are the Mach. Number calculations for this stage:

(1) Impactor Flow Rate $(Q)=5.0 \mathrm{lpm}$

(2) Number of Jets $(N)=40$

(3) Diameter of a Jet $(D)=0.0152 \mathrm{~cm}$

(4) Velocity of gas in the jet $\left(V=1000 Q /\left(\pi D^{2} / 4\right)\right)=1377.8 \mathrm{~cm} \mathrm{~s}^{-1}$

(5) Velocity of Sound @ NTP $\left(N_{\mathrm{S}}\right)=343500 \mathrm{~cm} \mathrm{~s}^{-1}$

(6) Mach Number for the sixth stage $\left(N / N_{s}\right)=0.004$

Since the Mach Number is less than 0.005 , the bias in the particle size measurements can be considered negligible (Biswas et al., 1987). 


\section{APPENDIX - VII}

\section{Calculation of MMD from MMAD Data}

The Aerodynamic Particle Diameter is the diameter of a unit density $\left(\rho_{p}=1\right)$ sphere that has the same settling velocity as the particle. The particle size distribution obtained from a cascade impactor is based on mass median aerodynamic diameter (MMAD) from which mass median diameter (MMD) can be determined by equating the settling velocity expressions with and without the particle density.

$$
V_{s}=\frac{\rho_{p} M M D^{2} g}{18 \mu}=\frac{M M A D^{2} g}{18 \mu}
$$

Equation VI-1 reduces to

$$
M M D=\frac{M M A D}{\sqrt{\rho_{p}}}
$$

Equation VI-2 was used to convert the observed MMAD's to MMD's used in the analysis.

These values for different tesis are presented in Table VII-1. 
Table VII-1 :Calculated MMD's for the Hygroscopic and Non-Hygroscoplc Tests

\begin{tabular}{|c|c|c|}
\hline RH (\%) & MMAD $(\mu \mathrm{m})$ & $\operatorname{MMD}(\mu \mathrm{m})$ \\
\hline \multicolumn{3}{|c|}{$0.5 \mu \mathrm{m}$ nominal MMD Aluminum Oxide $\left(\rho=3.9 \mathrm{~g} \mathrm{~cm}^{-3}\right)$} \\
\hline 1 & 1.07 & 0.54 \\
\hline 1 & 1.22 & 0.62 \\
\hline 35 & 1.05 & 0.53 \\
\hline 35 & 1.13 & 0.57 \\
\hline 80 & 1.28 & 0.85 \\
\hline 90 & 1.36 & 0.69 \\
\hline 95 & 1.48 & 0.75 \\
\hline 100 & 1.44 & 0.73 \\
\hline 100 & 1.24 & 0.63 \\
\hline \multicolumn{3}{|c|}{$1.0 \mu \mathrm{m}$ nominal MMD Aluminum Oxide $\left(p=3.9 \mathrm{~g} \mathrm{~cm}^{-3}\right)$} \\
\hline 1 & 1.96 & 0.99 \\
\hline 35 & 2.62 & 1.33 \\
\hline 35 & 2.03 & 1.03 \\
\hline 80 & 2.11 & 1.07 \\
\hline 90 & 2.21 & 1.12 \\
\hline 100 & 2.11 & 1.07 \\
\hline 100 & 2.57 & 1.30 \\
\hline \multicolumn{3}{|c|}{$0.5 \mu \mathrm{m}$ nominal MMD NaCl $\left(p=2.164 \mathrm{~g} \mathrm{~cm}^{-3}\right)$} \\
\hline 35 & 0.81 & 0.55 \\
\hline 55 & 0.82 & 0.56 \\
\hline 65 & 0.93 & 0.63 \\
\hline \multicolumn{3}{|c|}{$1.0 \mu \mathrm{m}$ nominal MMD NaCl $\left(\rho=2.164 \mathrm{~g} \mathrm{~cm}^{-3}\right)$} \\
\hline 35 & 1.78 & 1.21 \\
\hline 55 & 2.13 & 1.45 \\
\hline 67 & 3.12 & 2.12 \\
\hline
\end{tabular}




\section{APPENDIX VIII}

\section{Data used for Cake Porosity Estimation}

The data shown in Table VIII has been used to estimate the cake porosities in accordance with the method described in chapter 3 (section 3.3).

Table VIII : Cake Thickness ( $\left.t_{\text {cake }}\right)$ and the Porosity Data for the $47 \mathrm{~mm}$ Filters

\begin{tabular}{|c|c|c|c|c|c|}
\hline $\begin{array}{l}\text { RH } \\
(\mathbf{X})\end{array}$ & 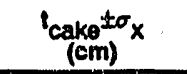 & $\begin{array}{l}\Delta M \\
(g)\end{array}$ & $\begin{array}{l}v_{\text {cake }} \\
\left(\mathrm{cm}^{\prime}\right)\end{array}$ & $\begin{array}{c}P_{\text {cake }} \\
(9 \mathrm{~cm})\end{array}$ & e \\
\hline \multicolumn{6}{|c|}{$0.5 \mu \mathrm{m}$ nominal MMD Aluminum Oxide } \\
\hline 1 & $0.0196 \pm 0.0047$ & 0.0432 & 0.2496 & 0.1731 & 0.95 \\
\hline 1 & $0.0159 \pm 0.0039$ & 0.0443 & 0.2025 & 0.2188 & 0.24 \\
\hline 35 & $0.0122+0.0024$ & 0.0479 & 0.1553 & 0.3084 & 0.92 \\
\hline 35 & $0.0112 \pm 0.0039$ & 0.0404 & 0.1426 & 0.2833 & 0.93 \\
\hline 90 & $0.0179 \pm 0.0035$ & 0.0511 & 0.3158 & 0.1840 & 0.94 \\
\hline 95 & $0.0295 \pm 0.0061$ & 0.0889 & 0.3762 & 0.2363 & 0.24 \\
\hline 100 & $0.0260 \pm 0.0028$ & 0.1234 & 0.3311 & 0.3727 & 0.90 \\
\hline \multicolumn{6}{|c|}{ Average Cake Porosity $\left(\epsilon_{a v}\right)=0.93$} \\
\hline \multicolumn{6}{|c|}{$1.0 \mu \mathrm{m}$ nominal MMD Aluminum Oxide } \\
\hline 1 & $0.0131 \pm 0.0020$ & 0.0908 & 0.1668 & 0.5444 & 0.86 \\
\hline 35 & $0.0138 \pm 0.0026$ & 0.0919 & 0.1757 & 0.5230 & 0.86 \\
\hline 35 & $0.0102 \pm 0.0038$ & 0.0772 & 0.1299 & 0.5943 & 0.23 \\
\hline 80 & $0.0183 \pm 0.0047$ & 0.1166 & 0.2330 & 0.5004 & 0.87 \\
\hline 90 & $0.0367 \pm 0.0021$ & 0.1489 & 0.4673 & 0.3186 & 0.82 \\
\hline 100 & $0.0181 \pm 0.0020$ & 0.1412 & 0.2305 & 0.6126 & 0.84 \\
\hline \multicolumn{6}{|c|}{ Average Cake Porosity $\left(\varepsilon_{\mathrm{GV}}\right)=0.87$} \\
\hline \multicolumn{6}{|c|}{$0.5 \mathrm{\mu m}$ nominal MMD $\mathrm{NaCl}$} \\
\hline 35 & $0.0095 \pm 0.0037$ & 0.0435 & 0.1210 & 0.3595 & 0.80 \\
\hline 55 & $0.0140 \pm 0.0067$ & 0.0696 & 0.1783 & 0.3904 & 0.77 \\
\hline 65 & $0.0112 \pm 0.0054$ & 0.0925 & 0.1426 & 0.6487 & 0.60 \\
\hline \multicolumn{6}{|c|}{ Average Cake Porosity $\left(c_{a x}\right)=0.73$} \\
\hline \multicolumn{6}{|c|}{$1.0 \mu \mathrm{m}$ nominal $M M \mathrm{M} \mathrm{NaCl}$} \\
\hline 35 & $0.0161 \pm 0.0044$ & 0.8148 & 0.2050 & 0.5600 & 0.72 \\
\hline 55 & $0.0183 \pm 0.0029$ & 0.1764 & 0.2330 & 0.7570 & 0.64 \\
\hline 67 & $0.0303 \pm 0.0028$ & 0.1850 & 0.3858 & 0.4795 & 0.78 \\
\hline \multicolumn{6}{|c|}{ Average Cake Porosity $\left(e_{\mathrm{av}}\right)=0.71$} \\
\hline
\end{tabular}




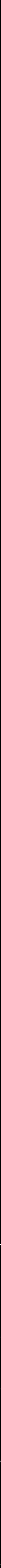


It is clear from Table V/III that the changes in the cake porosity are random and can not be ascribed to the changes in the RH. These changes could be because of the errors associated with the thickness measurements. However it is clearly seen that for a particie material, the porosity varied inversely as a function of particle size. For the nonhygroscopic aluminum oxide, the average polosities of the $0.5 \mu \mathrm{m} \mathrm{MMD}$ and the $1.0 \mu \mathrm{m}$ MMD particulate cakes were 0.94 and 0.87 respectively, whereas for the two sizes of the hygroscopic $\mathrm{NaCl}$ the average porosities were 0.73 and 0.71 respectively. Carr et al. (1969) and Rudnick (1978) also observed a similar inverse relationship between the porosity and particle size. 

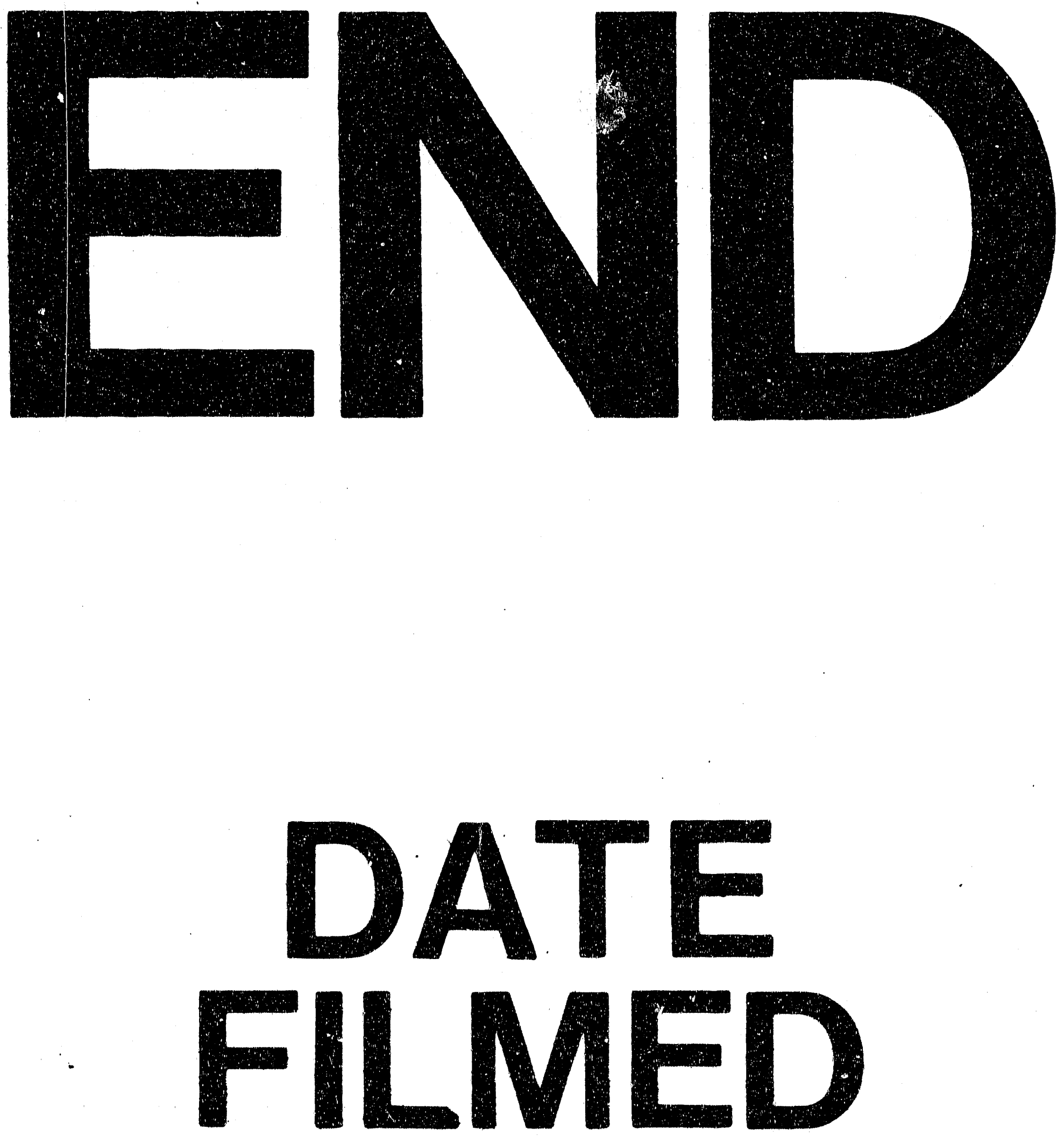

$\overline{3}$
$\overline{3}$

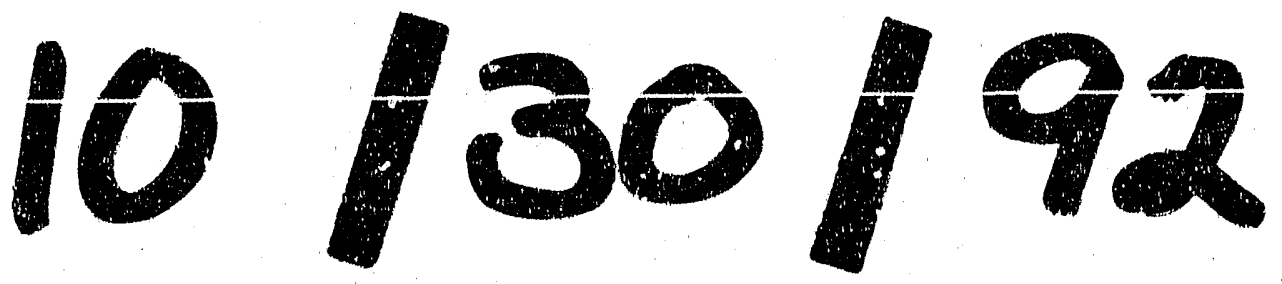


